\title{
Characterizing effects of feed restriction and glucagon-like peptide 2 administration on biomarkers of inflammation and intestinal morphology
}

\author{
S. K. Kvidera, ${ }^{*}$ E. A. Horst, ${ }^{*}$ M. V. Sanz Fernandez, ${ }^{*}$ M. Abuajamieh, ${ }^{*}$ S. Ganesan, ${ }^{*}$ P. J. Gorden, $†$ \\ H. B. Green, $\ddagger$ K. M. Schoenberg, $\ddagger$ W. E. Trout, $\ddagger$ A. F. Keating, ${ }^{*}$ and L. H. Baumgard*1 \\ *Department of Animal Science, and \\ †College of Veterinary Medicine, lowa State University, Ames 50011 \\ †Elanco Animal Health, Greenfield, IN 46140
}

\section{ABSTRACT}

Inadequate feed consumption reduces intestinal barrier function in both ruminants and monogastrics. Objectives were to characterize how progressive feed restriction (FR) affects inflammation, metabolism, and intestinal morphology, and to investigate if glucagonlike peptide 2 (GLP2) administration influences the aforementioned responses. Twenty-eight Holstein cows (157 $\pm 9 \mathrm{~d}$ in milk) were enrolled in 2 experimental periods. Period 1 [ $5 \mathrm{~d}$ of ad libitum (AL) feed intake] served as baseline for period $2(5 \mathrm{~d})$, during which cows received 1 of 6 treatments: (1) 100\% of AL feed intake (AL100; $\mathrm{n}=3$ ), (2) $80 \%$ of AL feed intake $(\mathrm{n}=5)$, (3) $60 \%$ of AL feed intake $(\mathrm{n}=5)$, (4) $40 \%$ of AL feed intake (AL40; $\mathrm{n}=5$ ), (5) $40 \%$ of $\mathrm{AL}$ feed intake + GLP2 administration (AL40G; $75 \mu \mathrm{g} / \mathrm{kg}$ of BW s.c. $2 \times / \mathrm{d} ; \mathrm{n}=5)$, or $(6) 20 \%$ of AL feed intake $(\mathrm{n}=5)$. As the magnitude of FR increased, body weight and milk yield decreased linearly. Blood urea nitrogen and insulin decreased, whereas nonesterified fatty acids and liver triglyceride content increased linearly with progressive FR. Circulating endotoxin, lipopolysaccharide binding protein, haptoglobin, serum amyloid $\mathrm{A}$, and lymphocytes increased or tended to increase linearly with advancing FR. Circulating haptoglobin decreased $(76 \%)$ and serum amyloid A tended to decrease $(57 \%)$ in AL40G relative to AL40 cows. Cows in AL100, AL40, and AL40G treatments were euthanized to evaluate intestinal histology. Jejunum villus width, crypt depth, and goblet cell area, as well as ileum villus height, crypt depth, and goblet cell area, were reduced $(36,14,52,22,28$, and $25 \%$, respectively) in AL40 cows compared with AL100 controls. Ileum cellular proliferation tended to be decreased (14\%) in AL40 versus AL100 cows. Relative to AL40, AL40G cows had improved jejunum and ileum morphology, includ-

Received May 24, 2017.

Accepted August 6, 2017.

${ }^{1}$ Corresponding author: baumgard@iastate.edu ing increased villus height (46 and 51\%), villus height to crypt depth ratio (38 and 35\%), mucosal surface area (30 and 27\%), cellular proliferation (43 and 36\%), and goblet cell area (59 and 41\%). Colon goblet cell area was also increased (48\%) in AL40G relative to AL40 cows. In summary, progressive FR increased circulating markers of inflammation, which we speculate is due to increased intestinal permeability as demonstrated by changes in intestinal architecture. Furthermore, GLP2 improved intestinal morphology and ameliorated circulating markers of inflammation. Consequently, FR is a viable model to study consequences of intestinal barrier dysfunction and administering GLP2 appears to be an effective mitigation strategy to improve gut health.

Key words: feed restriction, glucagon-like peptide 2, gut health

\section{INTRODUCTION}

There are various situations in animal agriculture where feed intake is suboptimal, either due to feed scarcity (e.g., shipping, drought, overcrowding) or resulting from an adaptive response (e.g., heat stress, immunoactivation). The decrease in energy and nutrient intake constrains animal performance below its genetic potential and jeopardizes efficiency and profitability. However, inadequate feed intake might affect productivity by mechanisms other than simply reduced substrate availability. Specifically, feed restriction (FR) and malnutrition cause intestinal barrier dysfunction in rodents, chickens, pigs, and humans (Rodriguez et al., 1996; Yamauchi et al., 1996; Welsh et al., 1998; Boza et al., 1999; Pearce et al., 2013), and we and others have demonstrated this also occurs in growing and lactating ruminants (Zhang et al., 2013; Kvidera et al., 2017a). Thus, the deleterious effect of FR on the intestinal barrier appears to transcend species and physiological states. Mechanistically, how FR negatively affects barrier integrity remains ill defined, but fasting and malnutrition reduce intestinal epithelial cell numbers, proliferation, migration rates, and villus height as well 
as increase intestinal cell loss rate and apoptosis (Ferraris and Carey, 2000). Furthermore, FR decreases antimicrobial secreting Paneth cell function, which compromises the immune defense capacity of the gut and alters the microbiome (Hodin et al., 2011; Le Floc'h et al., 2014). Due to its effect on intestinal barrier function, FR increases the risk of endotoxin translocation from the gut lumen into portal, lymph, and systemic circulation (Deitch et al., 1990).

Endotoxin infiltration of the intestinal barrier activates the immune system and causes a well-characterized inflammatory response (van Miert and Frens, 1968; Lohuis et al., 1988) coupled with a large energetic and AA requirement by stimulated leukocytes (Johnson, 2012; Iseri and Klasing, 2013; Kvidera et al., 2016, 2017b). Immunoactivation rearranges the hierarchy of nutrient partitioning away from economically important phenotypes, contributing to a reduction in profitability. Thus, it is necessary to develop appropriate models to test potential leaky gut mitigation strategies. Several chemically induced models of leaky gut are available [e.g., nonsteroidal anti-inflammatory drugs, gammasecretase inhibitors, and dextran sodium sulfate (Fortun and Hawkey, 2007; Wirtz et al., 2007; Kvidera et al., 2017a)], but these approaches are associated with side effects or are logistically difficult to deliver, particularly in ruminants where the rumen prevents many oral compounds from reaching the lower intestines. Propitiously, we and others have observed negative effects of FR on barrier function and systemic inflammation (Zhang et al., 2013; Pearce et al., 2013; Kvidera et al., 2017a). Thus, a simple FR protocol could potentially be a cheap and appealing intestinal barrier dysfunction model. However, the severity and duration of FR in the aforementioned literature varies considerably and its effects on gut health are not extensively studied in the ruminant animal; ergo, it is not clear what magnitude of FR is required to dependably compromise intestinal barrier function. Consequently, a primary objective of the current experiment was to identify a magnitude of FR that induces an inflammatory response mirroring the physiological characteristics of on-farm situations that cause leaky gut.

A potential mitigation strategy to improve intestinal barrier function is glucagon-like peptide 2 (GLP2) administration. Endogenous GLP2 is secreted by enteroendocrine cells in response to luminal nutrients and it has trophic effects on intestinal growth (Drucker and Yusta, 2014). Exogenous GLP2 administration prevents increased intestinal permeability in mouse models (Benjamin et al., 2000; Cameron and Perdue, 2005). Further, GLP2 administration improved expression of intestinal tight junction proteins, small intestine blood flow and growth, and reduced acute phase proteins in calves (Taylor-Edwards et al., 2011; Walker et al., 2015; Connor et al., 2017). Thus, a second objective was to evaluate whether GLP2 treatment ameliorates the negative effect of FR on intestinal health and systemic inflammation.

\section{MATERIALS AND METHODS}

\section{Animals and Sampling}

The Institutional Animal Care and Use Committee at Iowa State University approved all procedures involving animals. Twenty-eight lactating Holstein cows (157 \pm 9 DIM, $713 \pm 10 \mathrm{~kg}$ of BW, parity 2 to 4 ) were used in an experiment conducted in 2 replications. Cows were housed in individual box-stalls ( $4.57 \mathrm{~m}$ by $4.57 \mathrm{~m}$ ) at the Iowa State University Dairy Farm. Throughout the experiment, cows were milked twice daily (0600 and $1800 \mathrm{~h}$ ) and yields were recorded at each milking. Cows were individually fed a TMR formulated to meet or exceed the predicted requirements (NRC, 2001) of energy, protein, minerals, and vitamins (Table 1). Energy balance (EBAL) was calculated using the following equations: $\mathrm{EBAL}=$ energy intake - energy output, where energy intake $=1.6 \mathrm{Mcal} / \mathrm{kg} \times \mathrm{DMI}$ and energy output $=\left(\mathrm{NE}_{\mathrm{M}}=0.08 \mathrm{Mcal} / \mathrm{kg} \times \mathrm{BW}^{0.75}\right)+\left[\mathrm{NE}_{\mathrm{L}}=\right.$ milk yield $\times(0.029 \times$ fat $\%+0.0547 \times$ protein $\%+$ $0.0395 \times$ lactose \%)].

Table 1. Ingredients and composition of $\operatorname{diet}^{1}$

\begin{tabular}{|c|c|}
\hline Item & $\%$ of $\mathrm{DM}^{2}$ \\
\hline \multicolumn{2}{|l|}{ Ingredient } \\
\hline Corn silage & 42.8 \\
\hline Alfalfa hay & 19.7 \\
\hline Rolled corn & 18.1 \\
\hline Whole cotton & 8.6 \\
\hline High-protein soybean meal ${ }^{3}$ & 5.4 \\
\hline Soy Plus ${ }^{4}$ & 3.0 \\
\hline Ground corn & 2.3 \\
\hline \multicolumn{2}{|l|}{ Chemical analysis } \\
\hline $\mathrm{CP}$ & 16.7 \\
\hline $\mathrm{NDF}$ & 32.1 \\
\hline $\mathrm{ADF}$ & 21.8 \\
\hline $\mathrm{NE}_{\mathrm{L}}(\mathrm{Mcal} / \mathrm{kg}$ of $\mathrm{DM})$ & 1.6 \\
\hline
\end{tabular}

${ }^{1}$ Values represent an average of ration nutrient summary reports collected throughout the trial. Diet moisture averaged $43.56 \%$.

${ }^{2}$ Values are percent of DM unless otherwise indicated. Average nutrient levels: $4.41 \%$ fat, $0.84 \%$ Ca, $0.47 \%$ P, $0.37 \% \mathrm{Mg}, 0.20 \%$ S, $1.20 \%$ $\mathrm{K}, 0.45 \% \mathrm{Na}, 0.48 \% \mathrm{Cl}, 56.58 \mathrm{mg} / \mathrm{kg}$ of $\mathrm{Zn}, 64.85 \mathrm{mg} / \mathrm{kg}$ of Mn, 136.46 $\mathrm{mg} / \mathrm{kg}$ of $\mathrm{Fe}, 17.91 \mathrm{mg} / \mathrm{kg}$ of Cu, $0.22 \mathrm{mg} / \mathrm{kg}$ of Co, $0.27 \mathrm{mg} / \mathrm{kg}$ of Se, $0.85 \mathrm{mg} / \mathrm{kg}$ of I, $4,402.2 \mathrm{IU} / \mathrm{kg}$ of vitamin A, $1,438.8 \mathrm{IU} / \mathrm{kg}$ of vitamin $\mathrm{D}$, and $24.2 \mathrm{IU} / \mathrm{kg}$ of vitamin $\mathrm{E}$.

${ }^{3}$ Solvent-extracted soybean meal containing $54.5 \%$ CP, 35\% RUP $(\%$ of CP; DM basis).

${ }^{4}$ Cooker-expeller processed soybean meal produced by West Central Cooperative, Ralston, Iowa, containing $46.6 \%$ CP, 60\% RUP (\% CP; DM basis). 
The trial consisted of 2 experimental periods within each replication with all treatments represented in both replicates. Period 1 (P1) lasted $5 \mathrm{~d}$ and served as the baseline which yielded data for covariate analysis. During P1, cows were fed ad libitum; feed was distributed once daily $(0800 \mathrm{~h})$ and orts were collected before the next feeding. Period 2 (P2) lasted $5 \mathrm{~d}$ during which cows were allocated to 1 of 6 FR treatments: (1) ad libitum feed intake (AL100; $\mathrm{n}=3$ ), (2) $80 \%$ of P1 feed intake (AL80; $\mathrm{n}=5$ ), (3) $60 \%$ of $\mathrm{P} 1$ feed intake $($ AL60; $\mathrm{n}=5),(4) 40 \%$ of $\mathrm{P} 1$ feed intake + saline administration (AL40; $\sim 3 \mathrm{~mL}$ s.c. at 0700 and $1900 \mathrm{~h} ; \mathrm{n}$ $=5),(5) 40 \%$ of P1 feed intake + GLP2 administration (AL40G; $75 \mu \mathrm{g}$ of bovine GLP2/ $\mathrm{kg}$ of BW s.c. at 0700 and 1900 h; Elanco Animal Health, Greenfield, IN; n $=5$ ), or (6) $20 \%$ of P1 feed intake (AL20; $\mathrm{n}=5$ ). The GLP2 was the native 33 AA bovine sequence but with a glycine substituted for alanine in position 2 to confer resistance to dipeptidyl peptidase IV.

Samples of TMR were obtained on P2D1 and P2D5 for each replication (4 samples in total) for nutrient analysis (Dairyland Laboratories Inc., Arcadia, WI). Daily feed intake during P2 was determined by applying the desired percentage of FR to each cow's mean daily intake during $\mathrm{P} 1$. The calculated amount of feed was divided into 3 equal portions during P2 (0800, 1300, and $1800 \mathrm{~h}$ ) in order minimize metabolic variation due to gorging. During both P1 and P2, vitals were recorded twice daily at 0700 and $1900 \mathrm{~h}$. Heart rate and respiration rate were measured as beats or flank movements during a 15-s interval and were later transformed to beats/min and breaths/min, respectively. Rectal temperatures were measured using a digital thermometer (GLA M700, San Luis Obispo, CA). Individual milk samples for composition analysis were obtained daily during both periods from the PM milking. Samples were stored at $4^{\circ} \mathrm{C}$ with a preservative (bronopol tablet, D \& F Control System, San Ramon, CA) until analysis using AOAC approved infrared analysis equipment and procedures (AOAC International, 1995; method 972-16; Dairy Lab Services, Dubuque, IA). Body weights determined on d 1 of acclimation were used for calculating the GLP2 dose. Body weights were obtained again on d 5 of $\mathrm{P} 2$ to calculate BW change.

A jugular catheter was implanted in all cows before P1. Blood samples for metabolite and inflammatory biomarker analysis were collected daily at $1730 \mathrm{~h}$ during both periods into a glass tube containing $50 \mu \mathrm{L}$ of sterile heparin (Sagent Pharmaceuticals, Schaumburg, IL). Pyrogen-free serum samples for endotoxin analysis were collected on $\mathrm{d} 2$ and 4 of both $\mathrm{P} 1$ and $\mathrm{P} 2$ via coccygeal venipuncture. Prior to collection, the coccygeal area was scrubbed with alcohol-soaked gauze and the sample was collected into evacuated sterile serum collection tubes (BD Vacutainer, Franklin Lakes, NJ) and subsequently handled in sterile conditions. Serum samples were allowed to clot at room temperature for $1 \mathrm{~h}$ before centrifugation. Plasma and serum were harvested following centrifugation at $1,500 \times g$ for 15 min at $4^{\circ} \mathrm{C}$, and subsequently frozen at $-20^{\circ} \mathrm{C}$ until analysis. Samples for complete blood count analysis were collected on d 2 of P1 and d 4 of P2 via coccygeal venipuncture (3-mL Vacuette EDTA tubes, Greiner Bio-One, Monroe, NC), kept overnight at $4^{\circ} \mathrm{C}$, and submitted to the Iowa State University Department of Veterinary Pathology for analysis.

\section{Tissue Collection}

Liver biopsies were collected from all animals on $\mathrm{d} 2$ of P1 and d 5 of P2 as previously described (Rhoads et al., 2004). Briefly, the area was shaved, disinfected, and locally anesthetized using 2\% lidocaine (MWI Veterinary Supply Co., Glendale, AZ) before performing a percutaneous biopsy with a trocar. Samples were snap frozen in liquid nitrogen and stored at $-80^{\circ} \mathrm{C}$ until analysis. Biopsy incisions were then sutured using 3-0 nylon suture (Ethicon Inc., Somerville, NJ) and treated with a topical wound product (AluShield, Neogen Corp., Lexington, KY).

At the end of P2, cows were either returned to the ISU dairy herd or were transported to the Iowa State Livestock Infectious Disease Isolation Facility and euthanized via captive bolt gun followed by exsanguination. A total of 13 cows from AL100 ( $\mathrm{n}=3$ ), AL40 (n $=5)$, and AL40G $(\mathrm{n}=5)$ treatments were euthanized. Liver and intestinal tissues were harvested within 15 min of euthanasia. Intestinal samples (25-cm segments) were collected as follows: jejunum was collected $1 \mathrm{~m}$ proximal to the ileocecal junction, ileum was collected $18 \mathrm{~cm}$ proximal to the ileocecal junction, and descending colon was collected $50 \mathrm{~cm}$ proximal to the rectum. All intestinal segments were flushed with cold PBS to remove luminal contents and a $4-\mathrm{cm}$ section from the middle of the segment was collected and fixed in $10 \%$ neutral buffered formalin for later histological analysis.

\section{Laboratory Analyses}

Plasma insulin, nonesterified fatty acids (NEFA), glucose, BHB, lipopolysaccharide-binding protein (LBP), serum amyloid A (SAA), haptoglobin, and BUN concentrations were determined using commercially available kits validated in our laboratory (insulin, Mercodia AB, Uppsala, Sweden; NEFA, Wako Chemicals USA, Richmond, VA; glucose, Wako Chemicals USA Inc.; BHB, Pointe Scientific Inc., Canton, MI; LBP, Hycult Biotech, Uden, the Netherlands; SAA, Tridelta 
Development Ltd., Kildare, Ireland; haptoglobin, Immunology Consultants Laboratory Inc., Portland, OR; BUN, Teco Diagnostics, Anaheim, CA). Pyrogen-free serum samples were analyzed for endotoxin in duplicate using sterile procedures and a Pierce Limulus Amebocyte LAL Chromogenic Endotoxin Quantitation Kit (no. 88282, Thermo Scientific, Rockford, IL).

Portions of the liver samples $(\sim 5.0 \mathrm{~g})$ were weighed, dried for $18 \mathrm{~h}$ at $102^{\circ} \mathrm{C}$, and reweighed after cooling to determine liver moisture percentage. Hepatic triglyceride (TG) content was measured using a method from Morey et al. (2011). A 20-mg liver sample was weighed and homogenized with $500 \mu \mathrm{L}$ of chilled PBS. The homogenate was then centrifuged at $8,000 \times g$ for 2 min at $4^{\circ} \mathrm{C}$. Free glycerol was immediately determined using $10 \mu \mathrm{L}$ of supernatant via enzymatic glycerol phosphate oxidase method (Sigma-Aldrich, St. Louis, MO). An additional $300 \mu \mathrm{L}$ of supernatant was removed and incubated with $75 \mu \mathrm{L}$ of lipase (MP Biomedicals, Solon, $\mathrm{OH})$ at $37^{\circ} \mathrm{C}$ for $16 \mathrm{~h}$ before determining total glycerol using the same method. Free glycerol (before lipase digestion) was subtracted from total glycerol (after lipase digestion) to determine TG content, and this was expressed as a percentage of wet weight of the original sample. The intra-assay coefficients of variation for free glycerol and total glycerol were 1.9 and $0.8 \%$, respectively.

\section{Histological Analysis}

For histological analysis, $10 \%$ neutral buffered formalin-fixed ileum, jejunum, and colon samples were submitted to the Iowa State University Veterinary Diagnostic Laboratory for sectioning and periodic acid-Schiff (PAS) staining to quantify goblet cell area and villi morphology. One slide per tissue per cow was generated. Using a microscope (DMI3000 B Inverted Microscope, Leica, Bannockburn, IL) with an attached camera (12-bit QICAM Fast 1394, QImaging, Surrey, BC, Canada), 5 images per section of intestine were obtained at $50 \times$ magnification. All image processing and quantification was performed using Image J $1.48 \mathrm{v}$ (National Institutes of Health, Bethesda, MD). Periodic acid-Schiff stain was measured using the ImageJ color deconvolution tool with H PAS vector. Goblet cell area was expressed as a percentage of the total mucosal area stained by PAS. For villus measurements, 2 villi per image were measured for a total of 10 measurements per cow. Villus height was measured from the tip to the villus-crypt interface. Villus (v.) width was measured at mid-villus height. Crypt (c.) depth was measured from the villus-crypt opening to the lamina propria. Crypt width was measured at the villus-crypt interface level.
A mucosal surface area estimate was obtained using the mucosal-to-serosal amplification ratio $\mathrm{M}$ as previously reported by Kisielinski et al. (2002), where

$$
\mathrm{M}=\frac{\left[(\mathrm{v} \text {. width } \times \mathrm{v} \text {. length })+\left(\frac{\mathrm{v} \cdot \text { width }}{2}+\frac{\text { c. width }}{2}\right)^{2}-\left(\frac{\mathrm{v} \cdot \text { width }}{2}\right)^{2}\right]}{\left(\frac{\mathrm{v} \text {. width }}{2}+\frac{\text { c. width }}{2}\right)^{2}} .
$$

\section{Immunofluorescence Staining}

For immunofluorescence analysis, 10\% neutral buffered formalin-fixed jejunum, ileum, and colon were sectioned at a thickness of $5 \mu \mathrm{m}$ and mounted in the histology laboratory at the Iowa State University Veterinary Diagnostic Laboratory. Slides were deparaffinized using Citrisolv Hybrid Solvent (Fisher Scientific, Waltham, MA), rehydrated by $100 \%, 95 \%$, and $80 \%$ ethanol for 5 min each and then rinsed in distilled water. Antigen retrieval was performed by incubating slides in citrate buffer (sodium citrate, citric acid, Tween-20, water) in a laboratory microwave for $8 \mathrm{~min}$ and then slides were allowed to cool for $20 \mathrm{~min}$. Tissue sections were blocked in 5\% BSA (Sigma-Aldrich) in PBS for 90 to $180 \mathrm{~min}$. Primary antibody against proliferating cell nuclear antigen (PCNA; PC10 mAb, Cell Signaling Technology \#2586; 1:200 dilution), a marker of cellular proliferation, was applied to each section and incubated overnight at $4^{\circ} \mathrm{C}$. Slides were washed thrice in $1 \times$ PBS for $10 \mathrm{~min}$ and incubated in fluorescent secondary antibody [anti-mouse $\left.\operatorname{IgG}\left(\mathrm{H}^{+} \mathrm{L}\right) \quad \mathrm{F}(\mathrm{ab})_{2}\right)_{2}$ fragment, AlexaFluor 488 conjugate, Cell Signaling Technology \#4408; 1:1,000 dilution] for $1 \mathrm{~h}$ at room temperature. Slides were washed thrice in $1 \times$ PBS for $10 \mathrm{~min}$ and 4',6-diamidino-2-phenylindole stain was applied to each section. Slides were stained with BSA/BSA, primary antibody/BSA, BSA/secondary antibody as negative controls to ensure specificity of the staining pattern obtained. Images were collected on a Leica fluorescent microscope at $100 \times$ magnification. The integrated density of the PCNA staining was analyzed (3 random animals per treatment and 10 villi per animal) using ImageJ software, which includes the area of the villi section measured in the quantification.

\section{Statistical Analyses}

The effects of FR on most variables progressed with time, and thus data from P2 d5 were statistically analyzed using PROC MIXED of SAS (SAS Institute Inc., Cary, NC) with extent of FR as the fixed effect. Linear and quadratic effects of AL100, AL80, AL60, AL40, and AL20 treatments (not AL40G) were analyzed us- 
ing preplanned orthogonal contrasts. In addition, a preplanned contrast of AL40 and AL40G treatments was included. For endotoxin analysis, both P2D2 and P2D4 data were used but the effects of day and treatment by day interaction were not significant and were therefore removed from the model. For postmortem organ and histology data, preplanned contrasts of AL100 versus AL40 and AL40 versus AL40G were used. For liver TG, effect of treatment, period, and treatment by period interaction were assessed as well as linear and quadratic effects. Effect of replicate was included in the model and was removed if not significant. Each specific variable's P1 value (when available) served as a covariate. Results are reported as least squares means and considered different when $P \leq 0.05$ and tending to differ if $P<0.15$.

\section{RESULTS}

As dictated by experimental design, DMI linearly declined with increasing FR $(P<0.01$; Figure $1 \mathrm{~A})$. Similarly, a linear decrease occurred in both milk yield (Figure 1B) and EBAL (Table 2). No DMI, milk yield, or EBAL differences were detected between cows assigned to the AL40G and AL40 treatments $(P>0.15)$. A linear increase in milk fat content occurred with increased severity of FR $(P=0.01$; Table 2$)$. Advancing FR linearly decreased MUN, protein, and lactose content $(P<0.01$; Table 2$)$. No differences were observed in milk composition between cows in the AL40 and AL40G treatments.

Heart and respiration rates declined linearly with FR $(P \leq 0.04$; Table 2). Cows in the AL40G treatment had increased heart rate ( 7 beats per min) and rectal temperature $\left(0.3^{\circ} \mathrm{C}\right)$ compared with AL40 controls $(P$ $\leq 0.05$; Table 2). Unexpectedly, AL100 cows lost weight $(28 \mathrm{~kg})$, but BW loss increased with advancing FR severity (linear: $P<0.01$; Table 2 ). Body weight loss tended to be greater in AL40G relative to AL40 cows (60 vs. $40 \mathrm{~kg} ; P=0.09$ ). Within each period, cows were weighed at the same time relative to milking and feeding; however, BW loss data should be interpreted with caution because cows were not weighed at a similar time relative to either milking or feeding between P1 and P2 due to logistical constraints.

Overall, no difference was observed in circulating glucose $(P=0.33$; Figure $2 \mathrm{~A})$. Both circulating insulin and BUN decreased linearly $(P<0.01$; Figures $2 \mathrm{~B}$ and $2 \mathrm{C})$, whereas plasma NEFA increased linearly $(P<$ 0.01; Figure 2D) with increasing FR. Circulating BHB tended to differ $(P=0.07)$ between treatments with AL20 cows having the highest levels (51\% above AL100 controls; Figure 2E). Relative to AL40 controls, AL40G cows tended to have decreased circulating glucose $(60$ vs. $66 \mathrm{mg} / \mathrm{dL} ; P=0.08$; Figure $2 \mathrm{~A})$ and increased circulating BUN $(27 \% ; P=0.03$; Figure $2 \mathrm{C})$.

Circulating endotoxin, haptoglobin, SAA, and LBP increased or tended to increase linearly with advancing $\mathrm{FR}(P \leq 0.08$; Figures $3 \mathrm{~A}, 3 \mathrm{~B}, 3 \mathrm{C}$, and $3 \mathrm{D})$. A quadratic effect was detected for the insulin-to-DMI ratio where AL100 and AL20 treatments did not differ and AL80 and AL60 treatments were decreased $~ 50 \%$ relative to AL100 and AL20 $(P<0.01$; Figure $3 \mathrm{E})$. Circulating lymphocytes increased with advancing FR $(P$ $=0.05 ;$ Figure $3 \mathrm{~F}$ ), but no treatment or contrast effects were observed on any other immune cell parameters, including total white blood cells, neutrophils, monocytes, eosinophils, and basophils (data not shown). In comparison with AL40 controls, AL40G cows had similar circulating endotoxin, but had decreased haptoglobin (76\%; $P=0.01$; Figure 3B) and tended to have decreased SAA levels (57\%; $P=0.11$; Figure 3C). Circulating LBP did not differ between AL40G cows and AL40 controls ( $P=0.34$; Figure 3D).

Relative to AL100 cows, AL40 cows had decreased jejunum villus width, jejunum crypt depth, ileum villus height, and ileum crypt depth $(36,14,22$, and $28 \%$ reduction, respectively; $P<0.01$; Figures $4 \mathrm{~A}, 4 \mathrm{~B}$, and 5 ), and ileum mucosal surface area tended to be decreased $(12 \% ; P=0.08$; Figures 4D and 5). Intestinal cellular proliferation, as measured by PCNA staining, tended to be decreased $14 \%$ in the ileum of AL40 relative to AL100 cows $(P=0.06$; Figures $4 \mathrm{E}$ and 6$)$. Goblet cell area was decreased 52 and $25 \%$ in the jejunum and ileum $(P \leq 0.01)$ and tended to be decreased $17 \%$ in the colon of AL40 compared with AL100 cows $(P=$ 0.06 ; Figures $4 \mathrm{~F}$ and 5$)$. No differences in villus height to crypt depth ratio between AL100 and AL40 treatments were detected $(P>0.10$; Figures $4 \mathrm{C}$ and 5$)$. In comparison with the AL40 treatment, AL40G cows had increased jejunum and ileum villus height (46 and $51 \%$ increase, respectively) and increased ileum crypt depth $(17 \% ; P \leq 0.01$; Figures $4 \mathrm{~A}, 4 \mathrm{~B}$, and 5$)$. In both jejunum and ileum, AL40G cows had increased villus height to crypt depth ratios and mucosal surface area (38 and 35\% increase, respectively, and 30 and $29 \%$ increase, respectively; $P<0.01$; Figures $4 \mathrm{C}, 4 \mathrm{D}$, and $5)$. The PCNA protein positive staining was increased in both jejunum (43\%) and ileum (36\%) of AL40G cows relative to AL40 controls $(P<0.01$; Figures $4 \mathrm{E}$ and 6$)$. Goblet cell area from AL40G cows was increased 59, 41, and $48 \%$ in the jejunum, ileum, and colon, respectively, relative to AL40 controls $(P<0.01$; Figures $4 \mathrm{~F}$ and 5$)$.

Liver TG content did not differ during P1 $(P>0.10)$. At the end of P2, liver TG content increased linearly with increased severity of FR $(P=0.01)$, mainly due to an $\sim 88 \%$ increase in AL40 and AL20 relative to AL100 cows (Figure 7). 


\section{DISCUSSION}

Appreciation is increasing for how intestinal barrier integrity influences performance in animal agriculture. Circumstances where the gastrointestinal barrier is compromised include weaning (Boudry et al., 2004; Moeser et al., 2007), heat stress (Baumgard and Rhoads, 2013; Pearce et al., 2013), rumen acidosis (Emmanuel et al., 2007; Khafipour et al., 2009; Minuti et al., 2014), and the periparturient period (Abuajamieh et al., 2016). Thus, identifying a mitigation strategy that could improve or ameliorate leaky gut would presum- ably enhance production efficiency in a variety of species. However, a standardized and easily implemented model to evaluate potential beneficial target molecules has not been established. Reduced feed intake causes intestinal barrier dysfunction in humans (Welsh et al., 1998), rodents (Holt et al., 1986; Ueno et al., 2011), chickens (Yamauchi et al., 1996), pigs (Carey et al., 1994; Pearce et al., 2013), and ruminant models (Zhang et al., 2013). Further, our preliminary data suggest that this is also the case in lactating cows (Kvidera et al., 2017a). Therefore, our objectives were to identify a magnitude of FR that affects circulating biomarkers

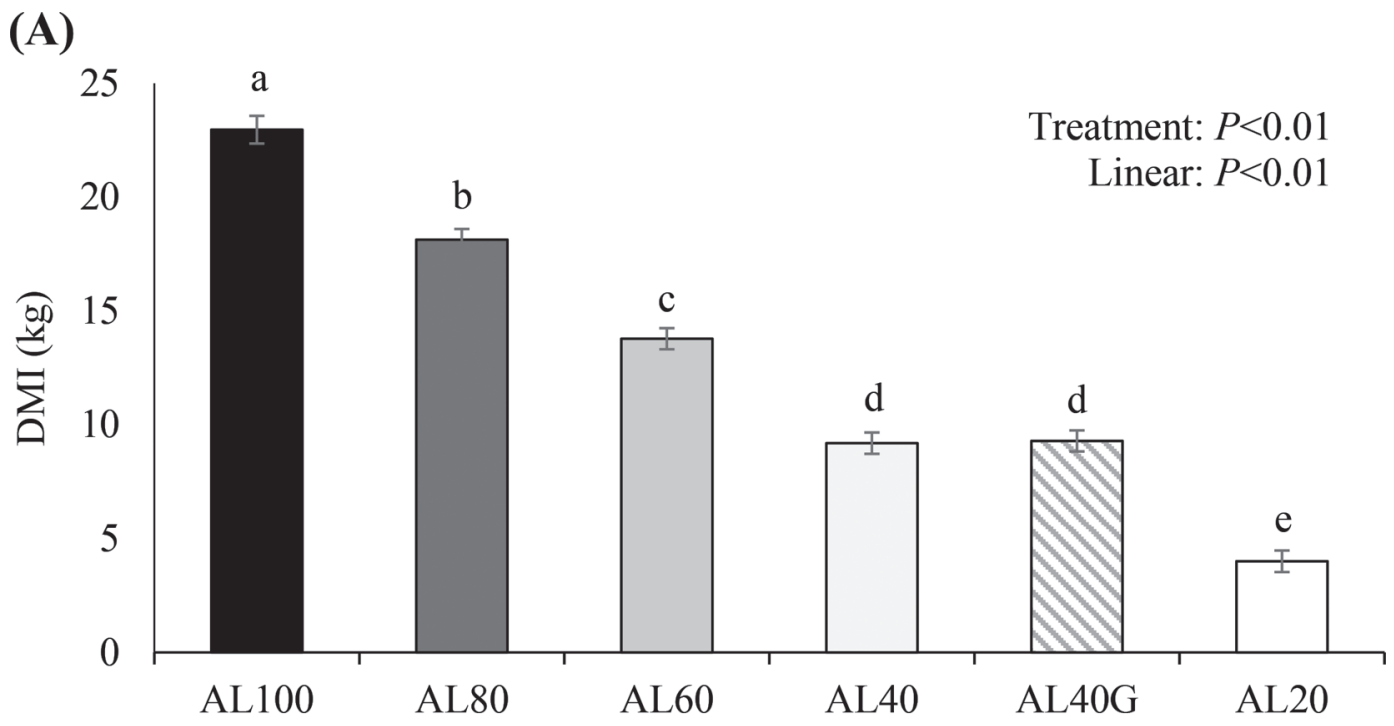

(B)

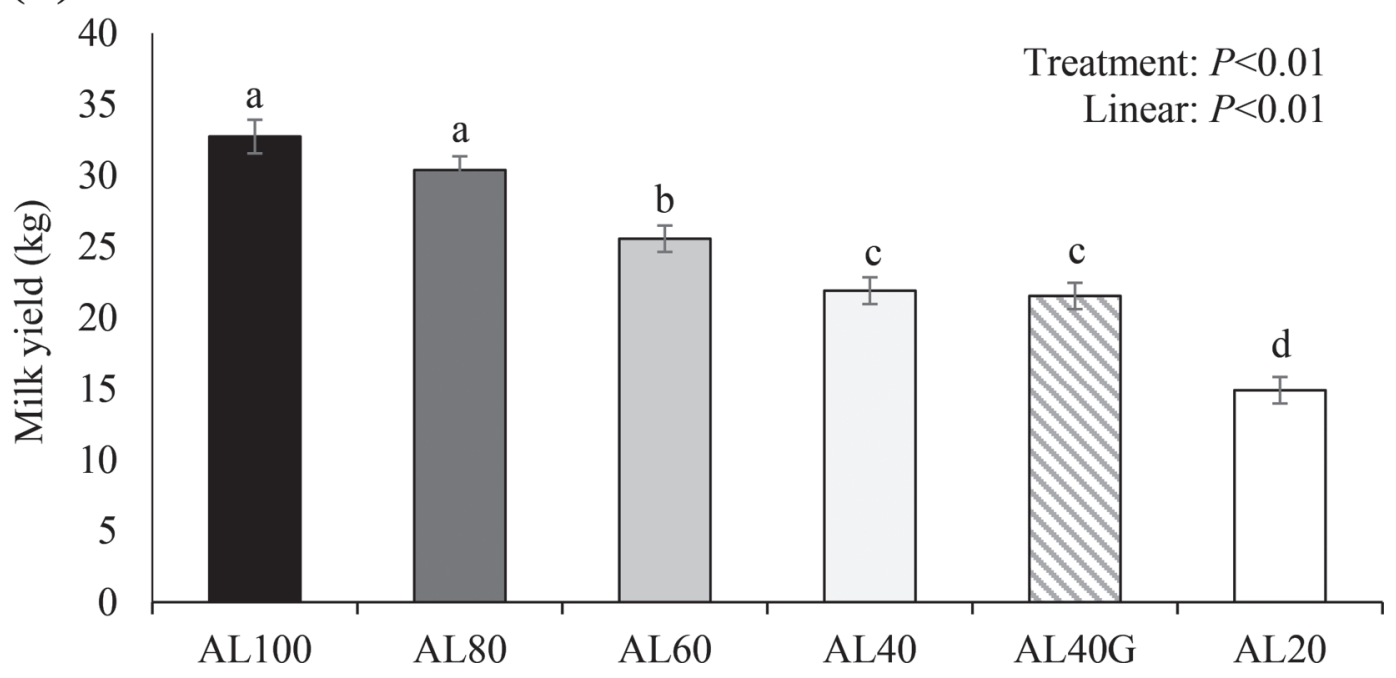

Figure 1. Effects of incremental feed restriction and glucagon-like peptide 2 (GLP2) treatment on (A) DMI and (B) milk yield on d 5 of treatment. Treatments include AL100 = ad libitum intake; AL80 = restricted to $80 \%$ of ad libitum intake; AL60 = restricted to $60 \%$ of ad libitum intake; AL40 = restricted to $40 \%$ of ad libitum intake + saline $(3 \mathrm{~mL}$ s.c. twice daily); AL $40 \mathrm{G}=$ restricted to $40 \%$ of ad libitum intake + glucagon-like peptide $2(75 \mu \mathrm{g} / \mathrm{kg}$ of BW s.c. twice daily); and AL20 = restricted to $20 \%$ of ad libitum intake. Results are expressed as LSM \pm SEM. Values with differing letters $(\mathrm{a}-\mathrm{e})$ denote differences $(P \leq 0.05)$ between treatments. 
Table 2. Effects of $5 \mathrm{~d}$ of incremental feed restriction and glucagon-like peptide 2 (GLP2) treatment on milk and health parameters

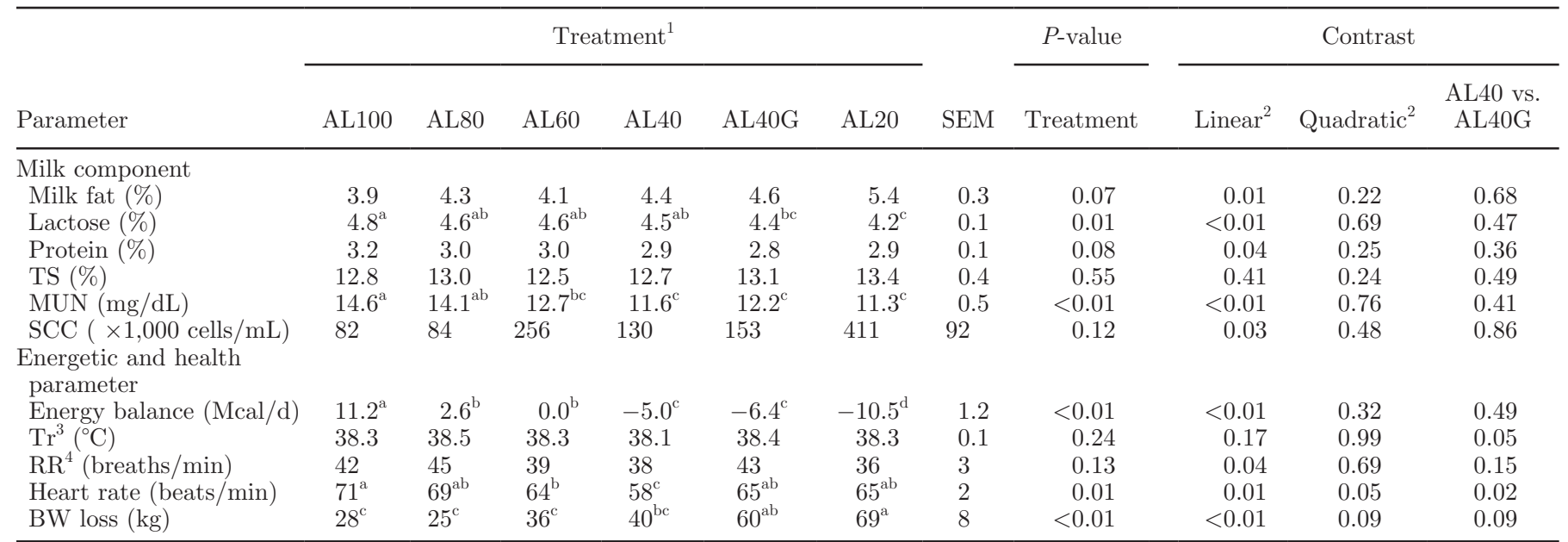

${ }^{\mathrm{a}-\mathrm{d}}$ Results are expressed as LSM. Values with differing letters denote differences $(P \leq 0.05)$ between treatments.

${ }^{1}$ Treatments: AL100 = ad libitum intake; AL80 = restricted to $80 \%$ of ad libitum intake; AL60 = restricted to $60 \%$ of ad libitum intake; AL40 $=$ restricted to $40 \%$ of ad libitum intake + saline ( $3 \mathrm{~mL}$ s.c. twice daily); AL40G = restricted to $40 \%$ of ad libitum intake + glucagon-like peptide $2(75 \mu \mathrm{g} / \mathrm{kg}$ of BW s.c. twice daily); AL20 = restricted to $20 \%$ of ad libitum intake.

${ }^{2}$ Assessed using AL100, AL80, AL60, AL40, and AL20 treatments.

${ }^{3}$ Rectal temperature.

${ }^{4}$ Respiration rate.

reflective of leaky gut, and to evaluate GLP2 administration as a potential mitigation strategy in lactating cows.

As expected, FR reduced milk yield and energy balance and increased BW loss, phenotypes demonstrating successful implementation of our experimental design. Further, the extent of milk yield and energy balance decreases was similar to other studies of comparable length and degree of FR (Carlson et al., 2006; Ferraretto et al., 2014). Metabolic changes observed during the current study are consistent with well-known hallmarks of FR in ruminants, including reduced circulating insulin (de Boer et al., 1985; Carlson et al., 2006; Ferraretto et al., 2014) and BUN (Bjerre-Harpøth et al., 2012; Lérias et al., 2015) and increased circulating NEFA (de Boer et al., 1985; Carlson et al., 2006; Ferraretto et al., 2014). Additionally, liver fat content was increased in animals restricted to 40 or $20 \%$ ad libitum intake, which agrees with similar models (Carlson et al., 2006).

In the current study, no overt health disorders were observed, so the increase in circulating inflammatory biomarkers observed ostensibly originated from the translocation of gut luminal content into circulation due to reduced intestinal barrier integrity. Circulating endotoxin was elevated with increasing severity of FR, and levels were similar to those observed by Khafipour et al. (2009). However, endotoxin data should be treated with caution as the Limulus Amebocyte Lysate assay measures endotoxin biological activity and not LPS bound to inflammatory mediators such as soluble cluster of differentiation 14 or LBP (Guerville and Boudry, 2016). Perhaps better markers of gut luminal content infiltration are acute-phase proteins (APP), which are produced by the liver as a secondary (nonlocal) response to toxic stimuli and have been widely used as indicators of systemic inflammation (Ceciliani et al., 2012). Circulating LBP, SAA, and haptoglobin were increased with progressive FR, indicating an incremental inflammatory response. Others have demonstrated that feed and water deprivation are the main contributors to the APP response in receiving feedlot cattle (Cappellozza et al., 2011; Marques et al., 2012). It is unclear why AL20 cows had a decreased APP response relative to less severely restricted cows. However, this is not unprecedented, as the magnitude of APP production can be impaired during severe malnourishment (Doherty et al., 1993; Reid et al., 2002). Circulating insulin is also acutely increased during inflammation (Baumgard et al., 2016; Kvidera et al., 2017a,b) and recent reports suggest insulin actually has potent anti-inflammatory effects (Chalmeh et al., 2013); however, differences in feed intake (and thus circulating nutrients, a major driver of insulin secretion) make this interpretation difficult. Utilizing an insulin-to-DMI ratio allows us to quantify the amount of circulating insulin per unit of DMI. The insulin-to-DMI ratio reached its nadir in the AL60 treatment before increasing to the point where the ratio from AL20 cows did not statistically differ 
(A)

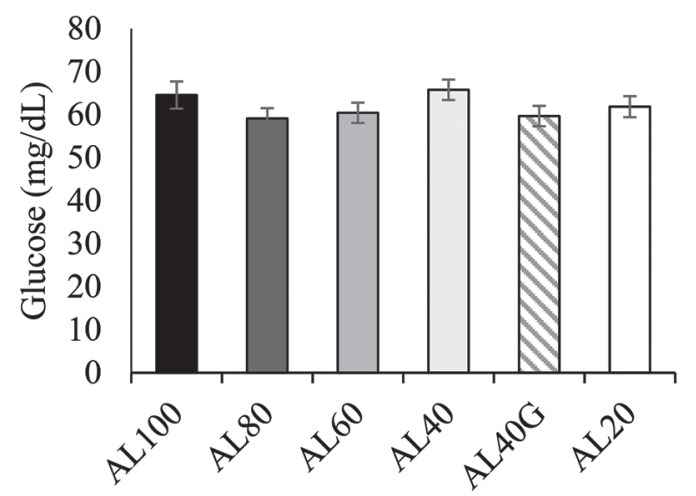

(C)

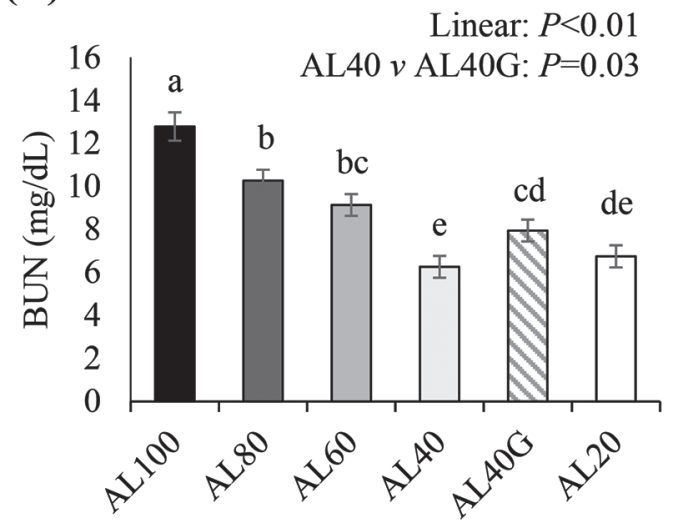

(E)

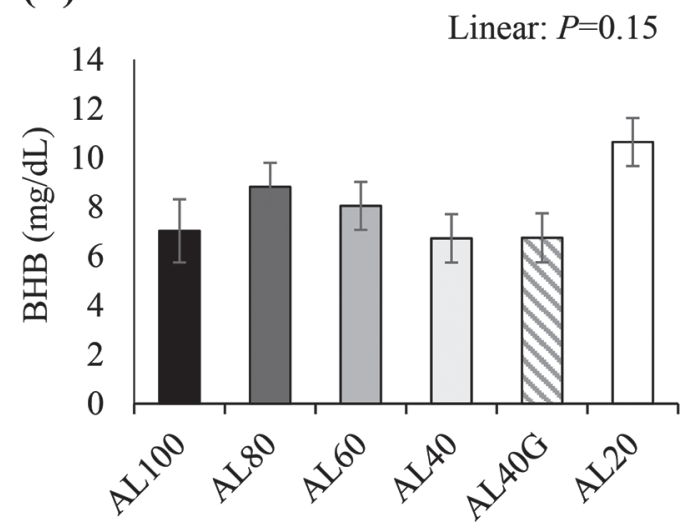

(B)

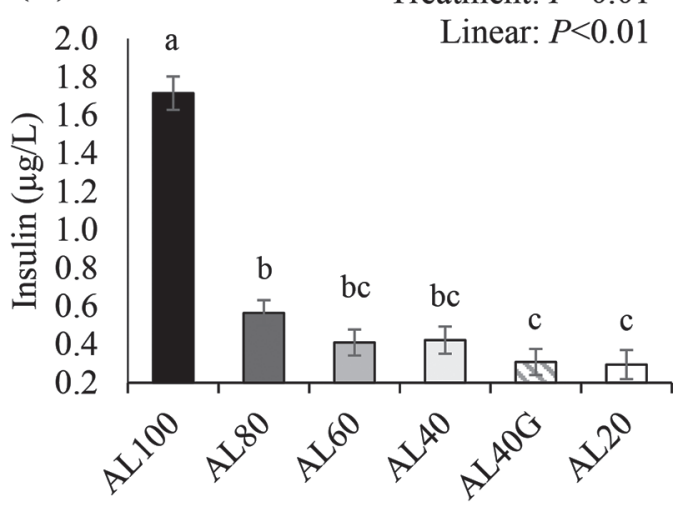

(D)

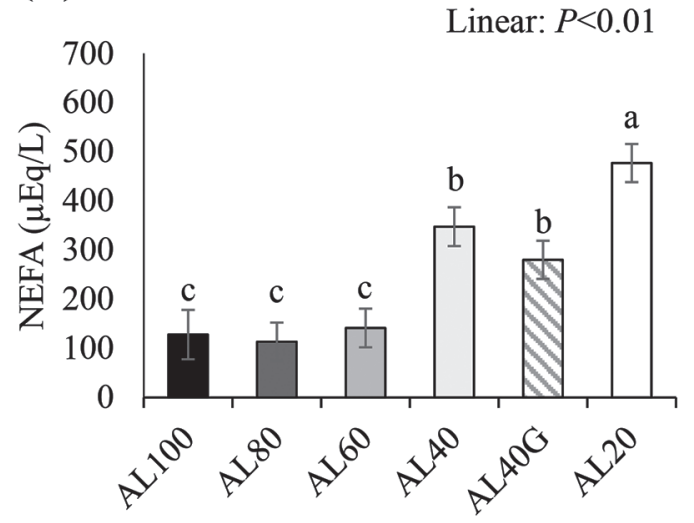

Figure 2. Effects of incremental feed restriction and glucagon-like peptide 2 (GLP2) treatment on circulating (A) glucose, (B) insulin, (C) BUN, (D) nonesterified fatty acids (NEFA), and (E) BHB on d 5 of treatment. Treatments include: AL100 = ad libitum intake, AL80 = restricted to $80 \%$ of ad libitum intake, AL60 = restricted to $60 \%$ of ad libitum intake, AL40 = restricted to $40 \%$ of ad libitum intake + saline $(3$ $\mathrm{mL}$ s.c. twice daily), AL40G $=$ restricted to $40 \%$ of ad libitum intake + glucagon-like peptide $2(75 \mu \mathrm{g} / \mathrm{kg}$ of BW s.c. twice daily), and AL20 $=$ restricted to $20 \%$ of ad libitum intake. Results are expressed as LSM \pm SEM. Values with differing letters $($ a-e) denote differences $(P \leq 0.05)$ between treatments.

from the AL100 controls. In the current study, the quadratic effect of FR on the insulin-to-DMI ratio further corroborates that extensive FR causes inflammation.

Reduced feed intake has deleterious effects on intestinal health (Ferraris and Carey, 2000). In the current study, FR to $40 \%$ of ad libitum intake for 5 d negatively affected intestinal architecture, characterized particularly by reduced ileum villus height and crypt depth. The decreased villus height is likely due to decreased cellular proliferation. Numerous other FR models demonstrate detrimental effects on intestinal histology, including reduced villus height in feed-restricted pigs 

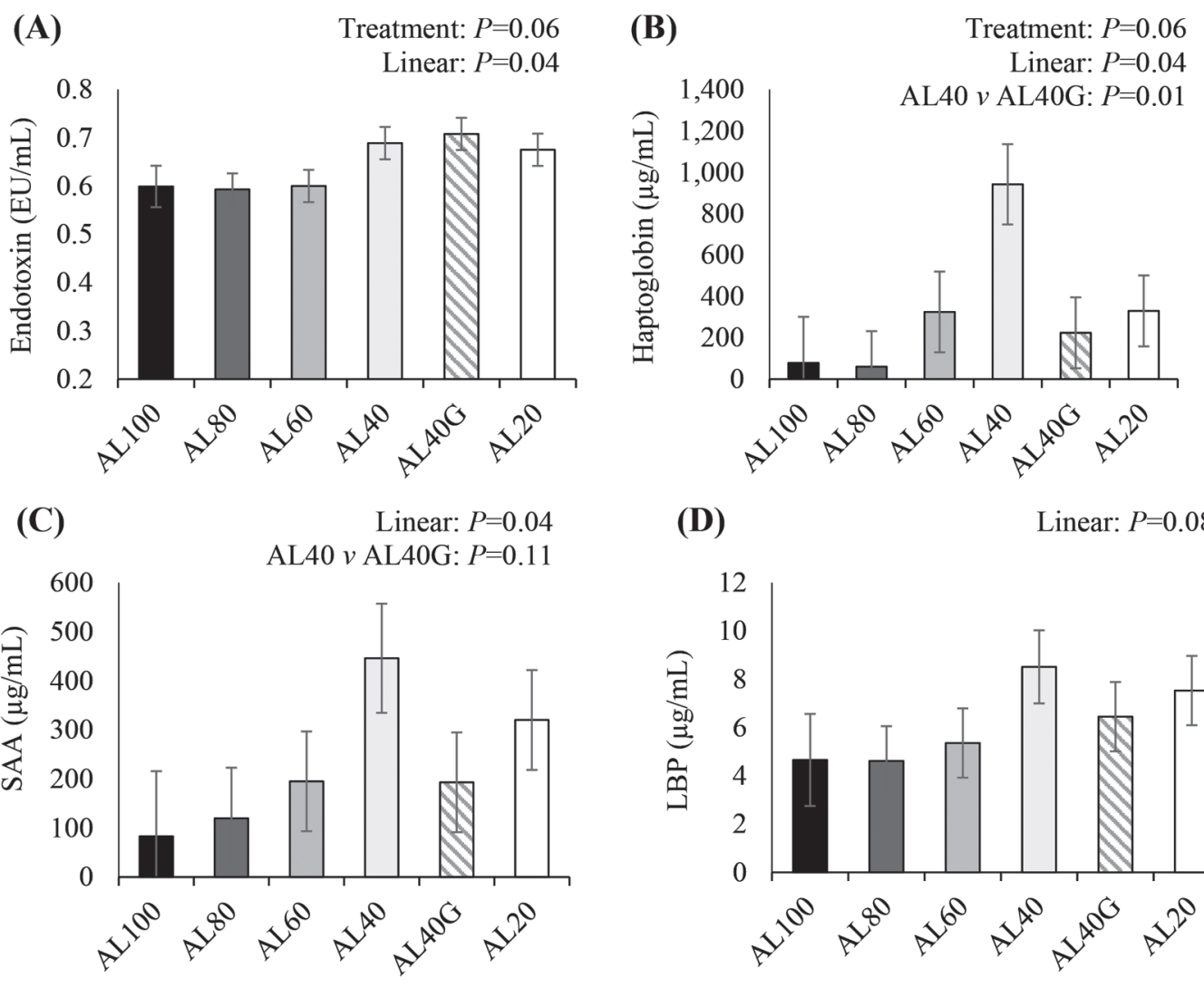
(D)
Linear: $P=0.08$

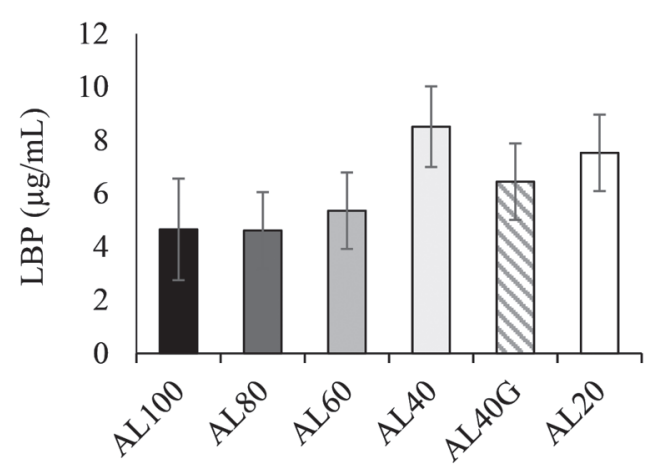

(E)

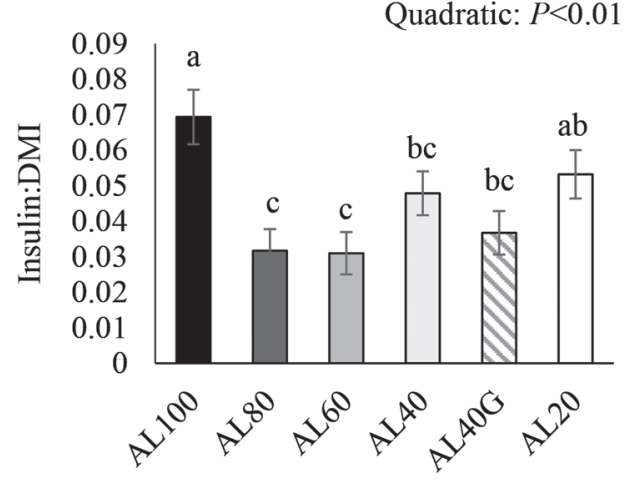

(F)

Linear: $P=0.05$

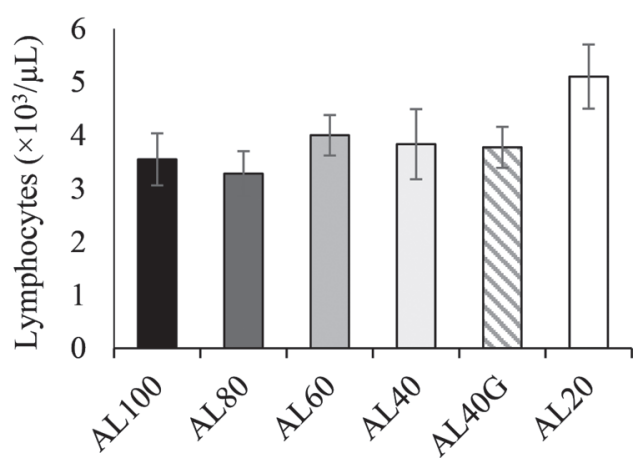

Figure 3. Effects of incremental feed restriction and glucagon-like peptide 2 (GLP2) treatment on (A) circulating endotoxin, (B) haptoglobin, (C) serum amyloid A (SAA), (D) LPS-binding protein (LBP), (E) insulin-to-DMI ratio (insulin:DMI), and (F) lymphocytes. Treatments include: AL100 = ad libitum intake, AL80 = restricted to $80 \%$ of ad libitum intake, AL60 = restricted to $60 \%$ of ad libitum intake, AL40 = restricted to $40 \%$ of ad libitum intake + saline $(3 \mathrm{~mL}$ s.c. twice daily), AL40G $=$ restricted to $40 \%$ of ad libitum intake + glucagon-like peptide $2(75 \mu \mathrm{g} / \mathrm{kg}$ of BW s.c. twice daily), and AL20 = restricted to $20 \%$ of ad libitum intake. Results are expressed as LSM \pm SEM. Values with differing letters $(\mathrm{a}-\mathrm{c})$ denote differences $(P \leq 0.05)$ between treatments.

(Carey et al., 1994; Pearce et al., 2013), chickens (Yamauchi et al., 1996), mice (Ueno et al., 2011), and rats (Holt et al., 1986). However, some FR models indicate no effect or even an increase in villus height (Holt et al., 1986; Chappell et al., 2003; Hodin et al., 2011; Tůmová et al., 2016). Reasons for the discrepancy within the literature could be the severity and duration of FR as well as the intestinal segment examined. Mechanisti- cally, fasting reduces intestinal epithelial cell numbers, cellular proliferation, and cellular migration rates, and this is coupled with increased rates of cellular loss and apoptosis, altogether contributing to changes in intestinal architecture and increased epithelial permeability (Ferraris and Carey, 2000; Chappell et al., 2003). Surprisingly, our PCNA immunohistochemistry stain indicated more proliferation occurring along the tips of 
the villi rather than in the crypts where proliferation is thought to normally occur. It is unclear exactly why this regional difference existed and further investiga- tion is certainly required. It is also possible nonintestinal cells could account for this unusual observation because macrophages express Pcna, which is alterable
(A)

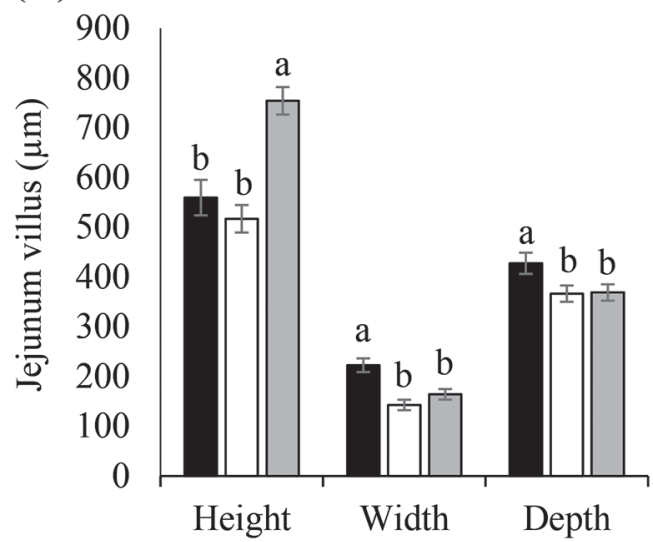

(C)

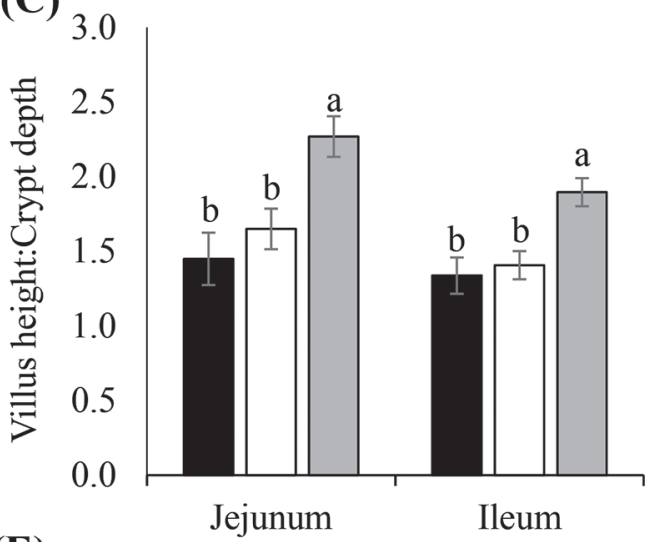

(E)

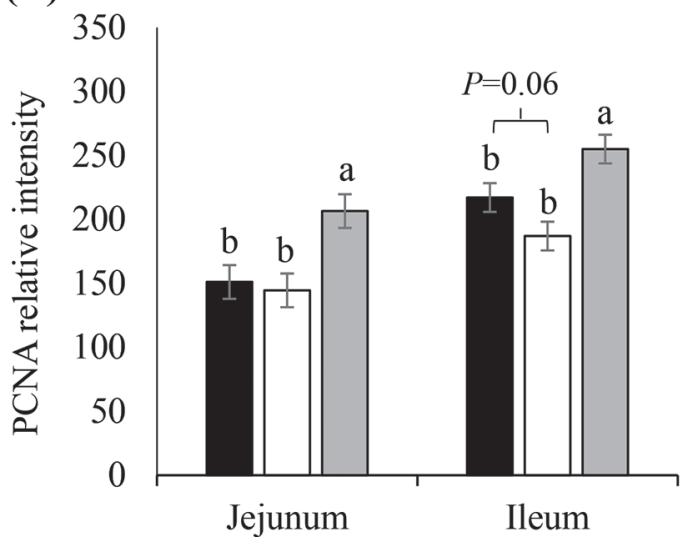

(B)

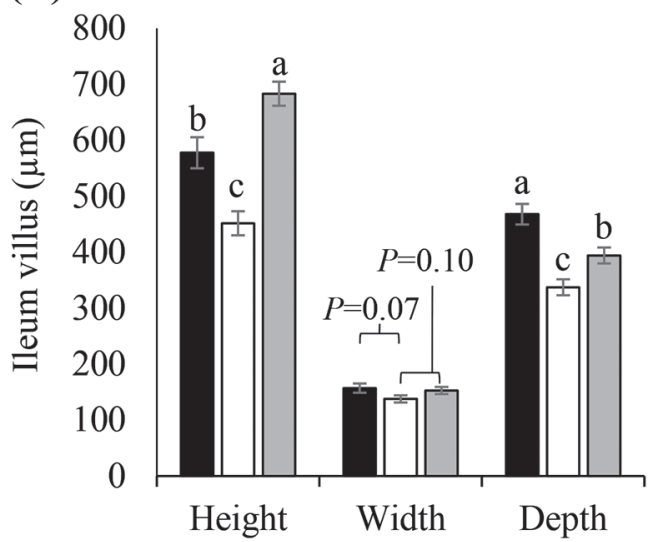

(D)

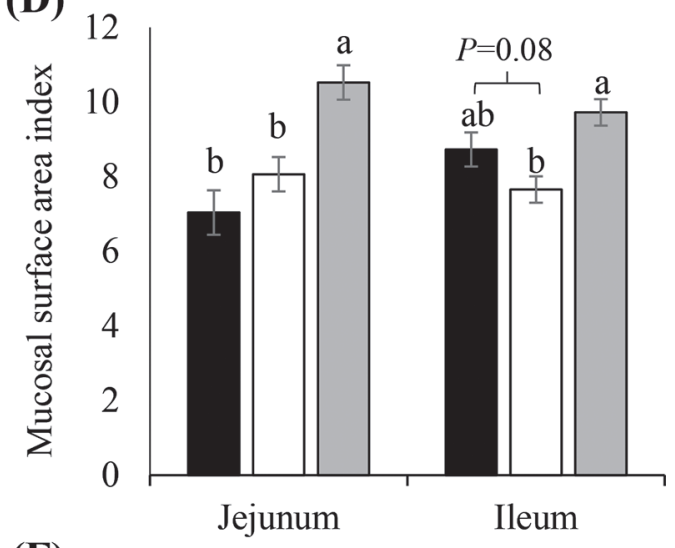

(F)

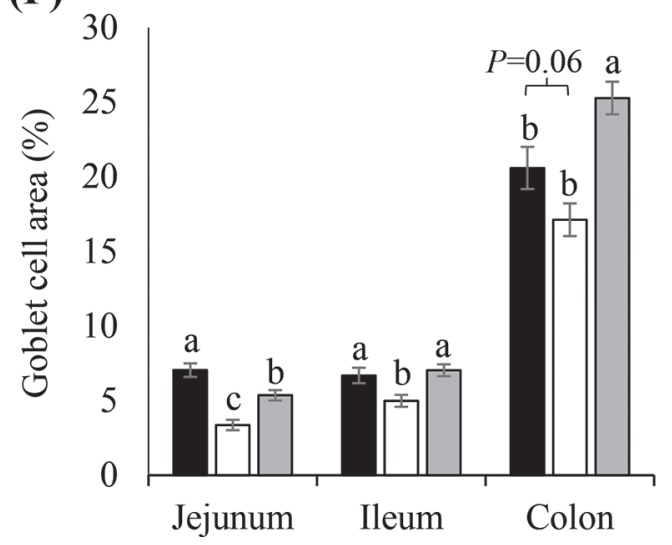

Figure 4. Effects of incremental feed restriction and glucagon-like peptide 2 (GLP2) treatment on (A) jejunum villus morphology, (B) ileum villus morphology, (C) villus height-to-crypt depth ratio in jejunum and ileum, (D) mucosal surface area in jejunum and ileum, (E) intensity of proliferating cell nuclear antigen (PCNA) protein in jejunum and ileum, and (F) goblet cell area as a percentage of epithelial area in jejunum, ileum, and colon. Treatments include AL100 = ad libitum intake; AL40 = restricted to 40\% of ad libitum intake + saline (3 mL s.c. twice daily); and AL40G $=$ restricted to $40 \%$ of ad libitum intake + glucagon-like peptide $2(75 \mu \mathrm{g} / \mathrm{kg}$ of BW s.c. twice daily). Results are expressed as LSM \pm SEM. Values with differing letters $(\mathrm{a}-\mathrm{c})$ denote differences $(P \leq 0.05)$ between treatments. Mucosal surface area is expressed as an M-index as described by Kisielinski et al. (2002). 

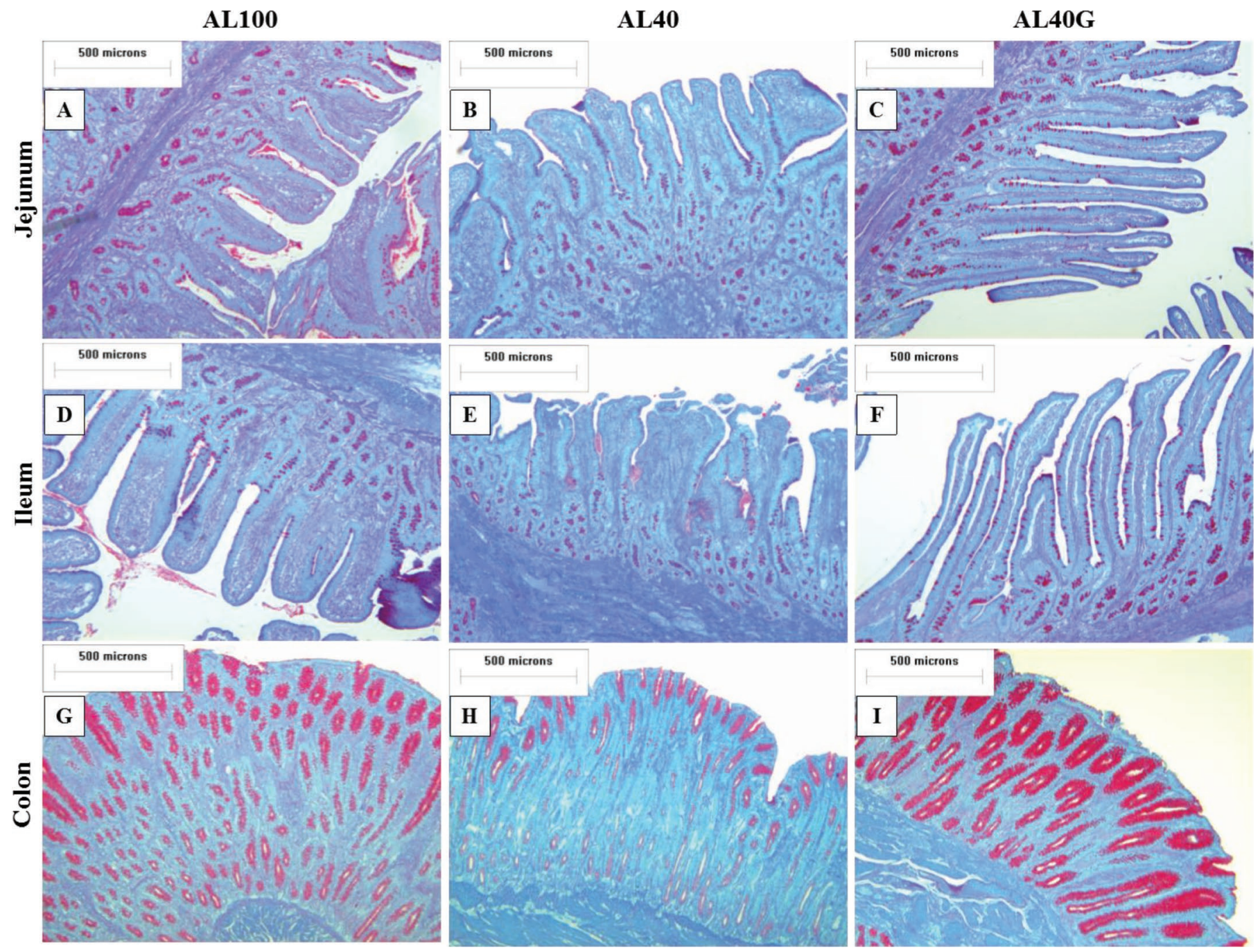

Figure 5. Representative images of periodic acid-Schiff stained (A) AL100 jejunum, (B) AL40 jejunum, (C) AL40G jejunum, (D) AL100 ileum, (E) AL40 ileum, (F) AL40G ileum, (G) AL100 colon, (B) AL40 colon, and (I) AL40G colon. AL100 = ad libitum intake; AL40 = restricted to $40 \%$ of ad libitum intake + saline ( $3 \mathrm{~mL}$ s.c. twice daily); AL40G = restricted to $40 \%$ of ad libitum intake + glucagon-like peptide $2(75 \mu \mathrm{g} /$ $\mathrm{kg}$ of BW s.c. twice daily). Dark stain indicates positive identification of mucosubstances. Color version available online.

by experimental treatment (Bueno-Silva et al., 2017; Thyagarajan et al., 2017). Additionally, the presence of macrophages can alter the abundance of PCNA in adjacent tissues (Shao et al., 2016) and altered PCNA abundance in porcine intestine has recently been demonstrated, and although staining was certainly more pronounced in the villi crypts, positive PCNA was detected in the tips, though to a much lesser degree (Kang et al., 2010). Although altered morphology does not necessarily indicate decreased barrier function, malnutrition and increased intestinal permeability have been reported in numerous species (Holt et al., 1986; Welsh et al., 1998; Boza et al., 1999). Further, altered intestinal barrier function has been demonstrated in studies where structural changes in villus morphology were similar to those observed in the current study (Ford et al., 1985; Pearce et al., 2013). Psychological stress, likely experienced during hunger, also increases gastrointestinal tract barrier permeability (Vanuytsel et al., 2014; de Punder and Pruimboom, 2015). This is likely mediated by tumor necrosis factor $\alpha$ and proteases released from mast cells upon central nervous system activation (Moeser et al., 2007; Overman et al., 2012).

The importance of proper barrier function cannot be overstated as the intestine is continuously exposed to potential pathogens and toxins (Mani et al., 2012). The human gastrointestinal tract has a surface area of $\sim 400 \mathrm{~m}^{2}$ (Murphy, 2012) and is continuously subjected to antigen contact (Mani et al., 2012). Micro- 
bial exposure is certainly more extensive in ruminants due to pregastric fermentation and the relative size of the gastrointestinal tract. The direct consequence of intestinal barrier dysfunction is increased leakage of luminal antigens into the submucosa and portal blood stream with the potential to initiate an inflammatory response. This can undoubtedly compromise production as immunoactivation is an energetically expensive process that redirects energy away from agriculturally productive purposes and compromises animal welfare (Johnson, 2012; Kvidera et al., 2017b). Therefore, assessing molecules or nutritional strategies to ameliorate gut barrier dysfunction, including exogenous GLP2, has gained recent attention in production agriculture (Thymann et al., 2014; Connor et al., 2016). Endog- enous GLP2 is a proglucagon-derived peptide secreted by enteroendocrine $\mathrm{L}$ cells in response to luminal nutrients (Drucker and Yusta, 2014). The intestinal trophic effects of GLP2 are mediated through increased mesenteric blood flow, greater nutrient uptake, and release of growth factors such as IGF-1, IGF-2, keratinocyte growth factor, and epidermal growth factor-ErbB family members (Connor et al., 2016). Exogenous GLP2 administration reduced intestinal permeability, hepatic bacterial cultures, and intestinal crypt apoptosis in stressed mouse models (Boushey et al., 1999; Cameron and Perdue, 2005). The authors are unaware of previous literature examining the effect of GLP2 in lactating dairy cattle; however, GLP2 receptors have been characterized in the lactating cow's gastrointestinal
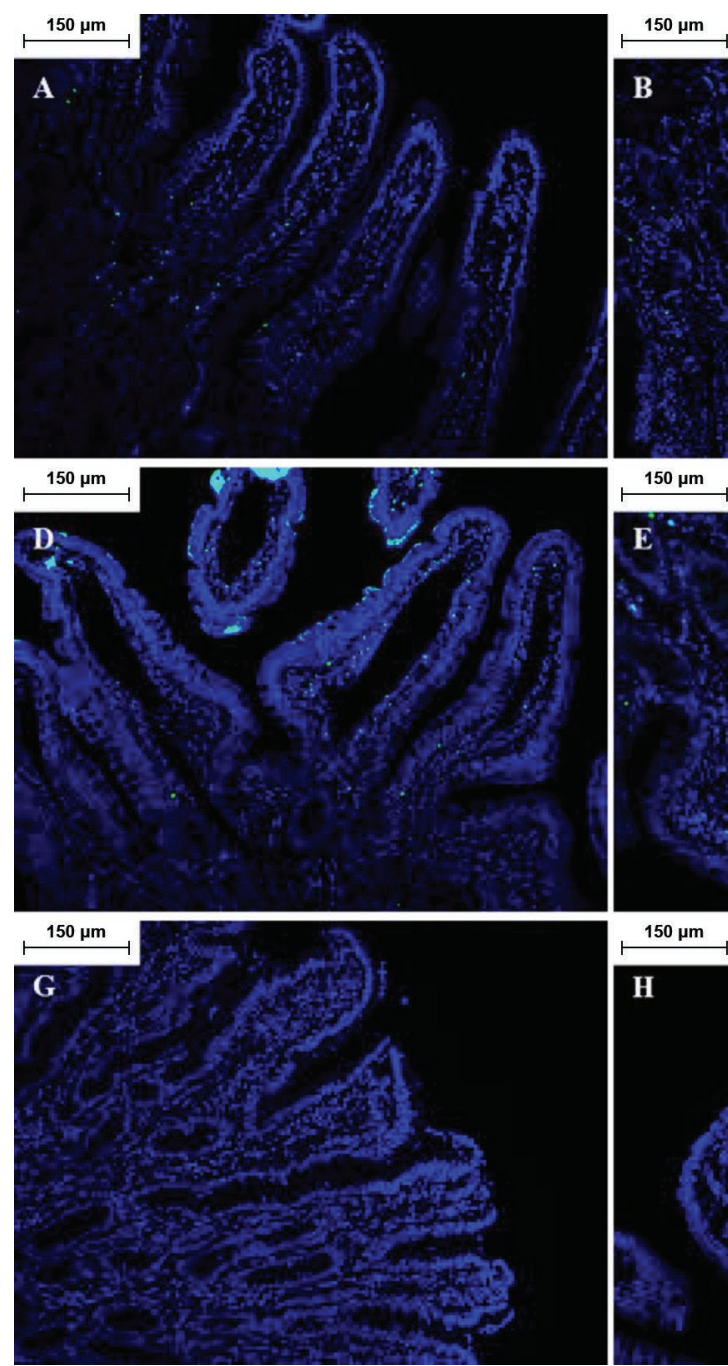
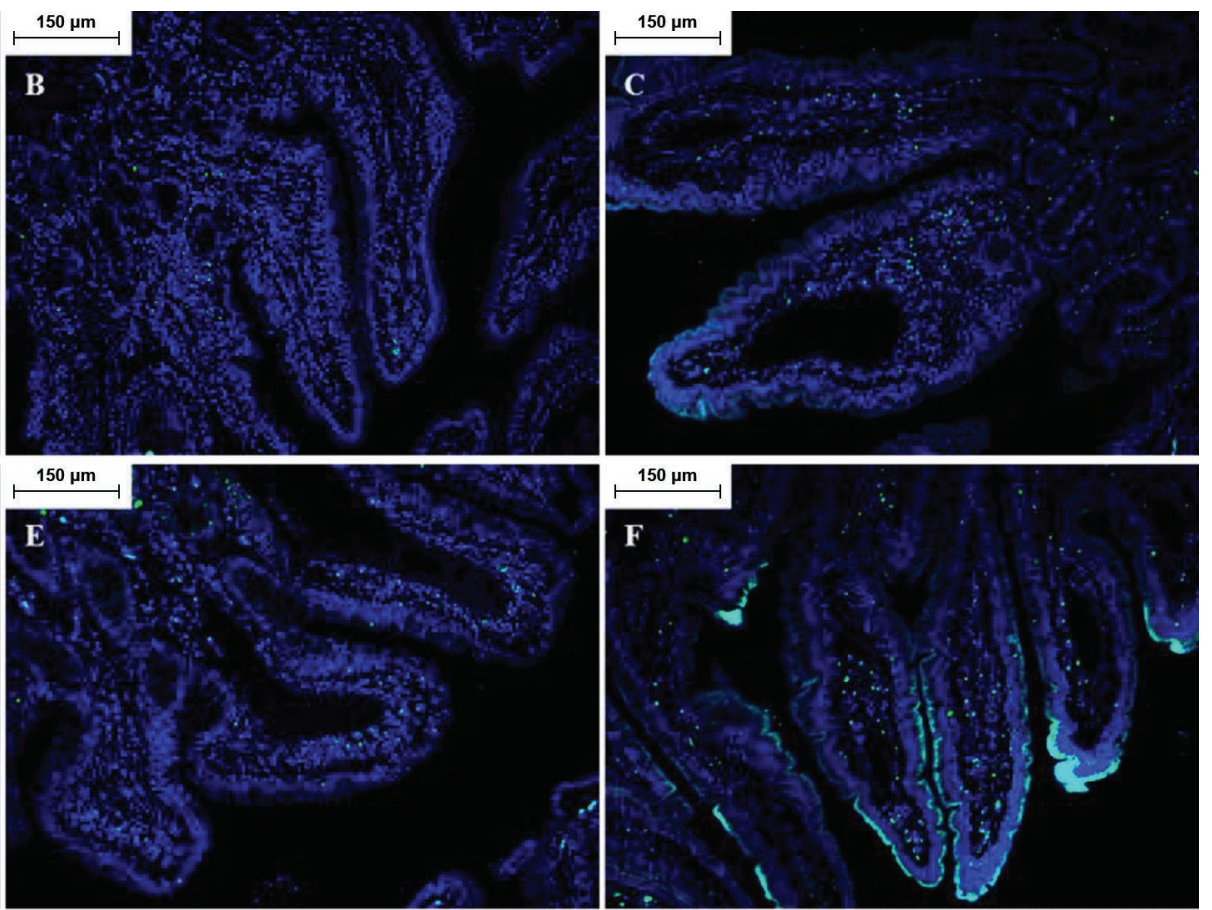

$150 \mu \mathrm{m}$

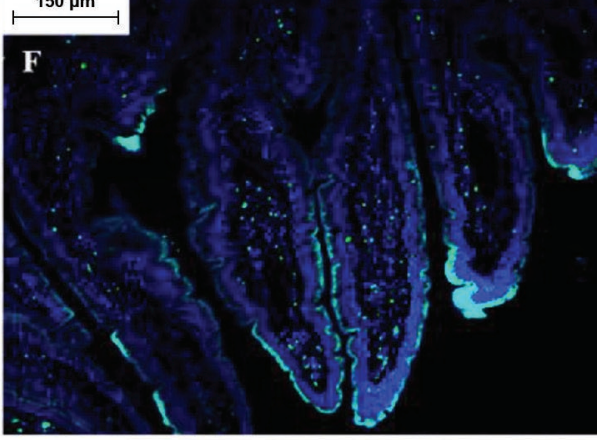

$150 \mu \mathrm{m}$

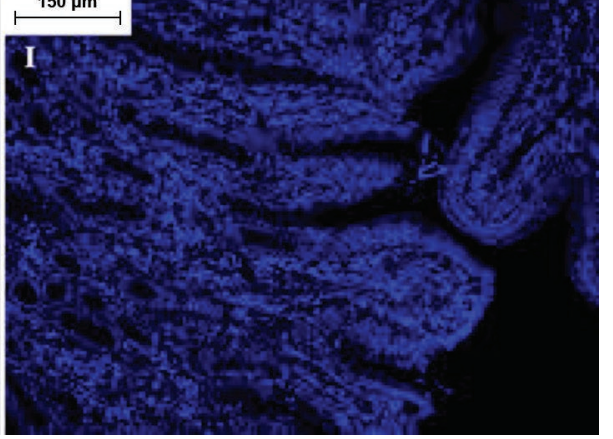

Figure 6. Representative image of proliferating cell nuclear antigen (PCNA) protein intensity in (A) AL100 jejunum, (B) AL40 jejunum, (C) AL40G jejunum, (D) AL100 ileum, (E) AL40 ileum, (F) AL40G ileum. Negative controls are (G) BSA/BSA, (H) primary antibody alone, and (I) secondary antibody alone. AL100 = ad libitum intake; AL40 = restricted to $40 \%$ of ad libitum intake + saline (3 mL s.c. twice daily); $\mathrm{AL} 40 \mathrm{G}=$ restricted to $40 \%$ of ad libitum intake + glucagon-like peptide $2(75 \mu \mathrm{g} / \mathrm{kg}$ of BW s.c. twice daily). Lighter coloration represents PCNA positive staining. Color version available online. 


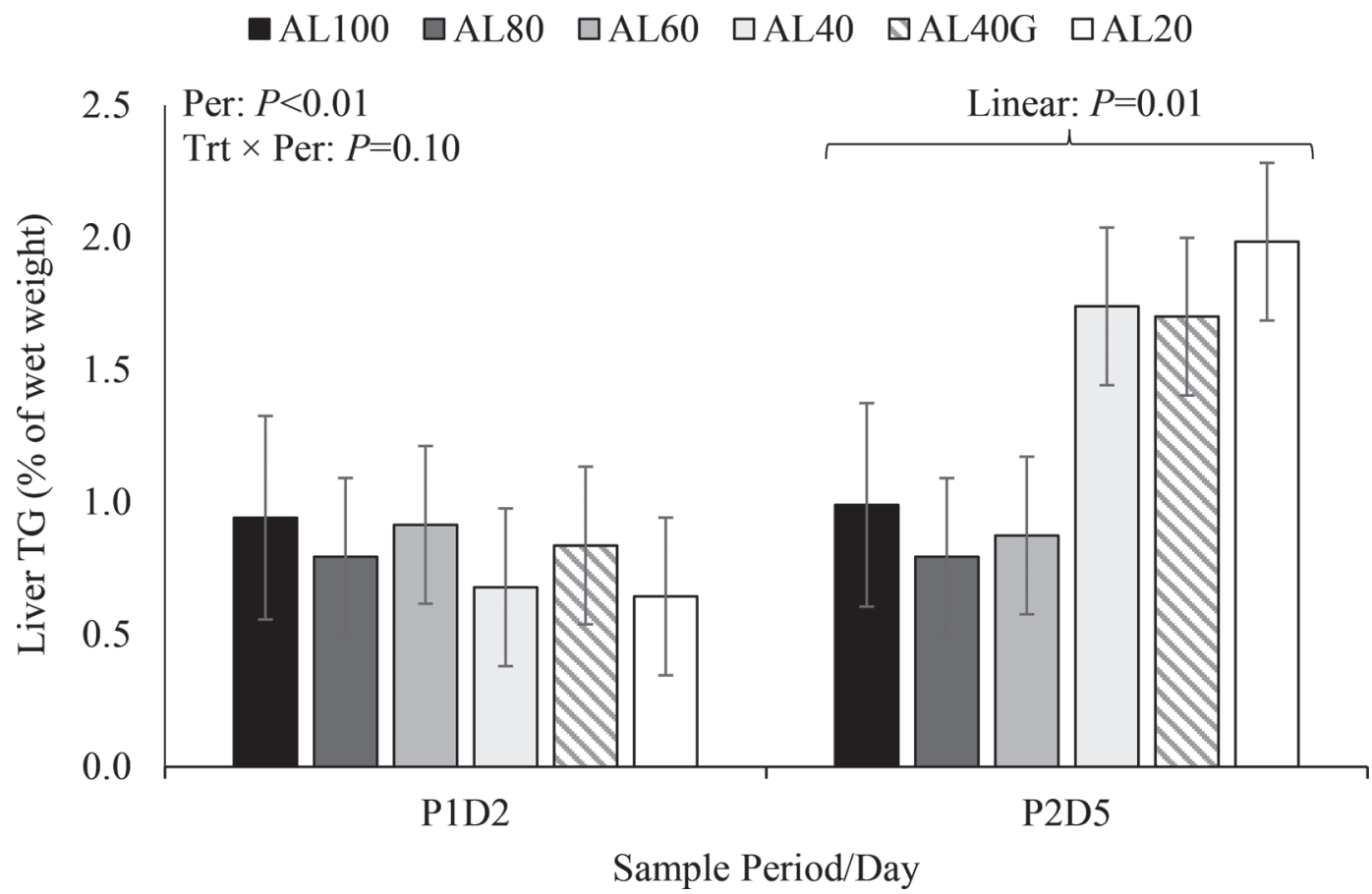

Figure 7. Effects of incremental feed restriction and glucagon-like peptide 2 (GLP2) treatment on liver triglyceride (TG) content. Treatments include AL100 = ad libitum intake; AL80 = restricted to $80 \%$ of ad libitum intake; AL60 = restricted to $60 \%$ of ad libitum intake; AL40 = restricted to $40 \%$ of ad libitum intake + saline $(3 \mathrm{~mL}$ s.c. twice daily); AL40G $=$ restricted to $40 \%$ of ad libitum intake + glucagon-like peptide $2(75 \mu \mathrm{g} / \mathrm{kg}$ of BW s.c. twice daily); and AL20 = restricted to $20 \%$ of ad libitum intake. Trt $=$ treatment; Per $=$ period; P1D2 = period 1 and d 2; P2D $5=$ period 2 and $\mathrm{d} 5$. Results are expressed as LSM \pm SEM.

tract (Connor et al., 2010). In calves, GLP2 administration increased small intestine tight junction protein expression, blood flow, and growth and reduced circulating APP (Taylor-Edwards et al., 2011; Connor et al., 2013; Walker et al., 2015; Connor et al., 2017). In the current study, administering GLP2 increased ileum villus height even above the ad libitum controls. Negative effects of FR on ileum mucosal area and goblet cell area of all 3 segments were also rescued or even improved (compared with ad libitum-fed controls) by GLP2 administration. Though FR did not affect villus height to crypt depth ratios, jejunum villus height, or jejunum mucosal surface area, GLP2 increased each of these parameters $\sim 30$ to $50 \%$ above ad libitum-fed control cows. Increased villus height in animals administered GLP2 is likely explained by increased cellular proliferation observed in both the jejunum and ileum. It is unclear why FR affected the ileum more than the jejunum, but it may be due to diminished nutrient availability from the proximal to distal intestine. Furthermore, regional differences are present in immune cell populations, which generally increase from proximal to distal intestine (Mowat and Agace, 2014), and FR is a psychologically stressful event where cortisol may induce intestinal permeability via mast-cell-dependent mechanisms (Vanuytsel et al., 2014). Differences in vascularization and blood flow between the jejunum and ileum may also play a role in section differences. Subtle changes in jejunum intestinal architecture also may not be detected due to the low number of cows used in this study. Regardless, these data clearly demonstrate the beneficial effects of GLP2 on the intestine in both treatments, which agrees with $\mathrm{Hu}$ et al. (2010) who also observed the trophic effects of GLP2 in both heat-stressed and healthy chickens. Further, administering GLP2 lowered circulating haptoglobin and SAA (76 and 57\%, respectively). A reduced circulating SAA response to coccidial infection was also observed in calves administered GLP2 (Connor et al., 2017). We hypothesize that the protective effect of GLP2 on intestinal permeability and subsequent prevention of endotoxin infiltration play a role in the APP reduction. Glucagon-like peptide 2 may also have a direct role in inhibiting inflammation because it stimulates antimicrobial peptide secretion by Paneth cells in the intestinal epithelium (Lee et al., 2012), which may reduce microbial load and subsequent microbial component leakage into systemic circulation. Furthermore, GLP2 can suppress the pro-inflammatory response of macrophages to LPS (Xie et al., 2014). Collectively, the histology and changes in APP profile strongly suggest that GLP2 improved gut barrier function. 
Despite its beneficial effects on intestinal health, GLP2 administration did not improve production parameters, as evidenced by similar milk yield and composition between AL40 and AL40G cows. This is not entirely surprising, as the experiment was knowingly underpowered to detect production differences. Additionally, employing the FR model limits potential positive effects GLP2 may have on feed intake. It would be of interest to study GLP2 administration during a natural model of stress with objectives of determining if GLP2 has a beneficial effect on feed intake or production and if this further improves intestinal growth and integrity. It is unclear whether the GLP2-induced decrease in circulating glucose is of biological relevance (66 vs. $60 \mathrm{mg} / \mathrm{dL}$ ), but it may be related to GLP2's neuroendocrine role in the gut-brain axis, which can suppress hepatic glucose production and increase insulin sensitivity (Guan, 2014). Injecting GLP2 did not influence circulating insulin, and this is not surprising as GLP2 does not directly modulate insulin secretion (Schmidt et al., 1985). Interestingly, GLP2 administration increased BUN (27\%) and the reasons behind this effect are not clear, but interpreting BUN in ruminants is difficult because it originates from both skeletal muscle catabolism and excessive rumen ammonia production.

Decreased intestinal barrier integrity has several negative consequences and thus research into ruminant intestinal health has gained recent attention (Connor et al., 2016; Steele et al., 2016). However, it is difficult to model leaky gut to test potential mitigation strategies. Various models exist to pharmaceutically induce intestinal barrier dysfunction, including nonsteroidal anti-inflammatory drugs, gamma-secretase inhibitors, and dextran sodium sulfate (Fortun and Hawkey, 2007; Wirtz et al., 2007; Kvidera et al., 2017a), but these approaches are difficult to administer in ruminants and are often associated with undesirable side effects. As previously mentioned, the severity and duration of FR documented in scientific literature varies considerably and its effects on gut health are not extensively studied in the ruminant animal, hence it is not clear what magnitude of FR is required to dependably compromise intestinal barrier function. In the current study, animals restricted to $40 \%$ of their ad libitum intake for $5 \mathrm{~d}$ exhibited a well-defined increase in inflammatory parameters. Intestinal architecture deterioration accompanied this inflammation, providing us confidence that intestinal dysfunction was likely the cause. One drawback to our FR model is that GLP2's potential benefits on feed intake are eliminated. Nevertheless, GLP2 administration improved intestinal health and subsequently reduced inflammatory parameters independent of any changes in feed intake.

\section{CONCLUSIONS}

Increasing severity of FR reduced milk yield and increased circulating endotoxin and APP as well as liver TG, and cows fed $40 \%$ of their ad libitum intake were most affected. Progressive FR causes intestinal barrier dysfunction characterized by reduced ileum villus height, mucosal surface area, and cellular proliferation as well as reduced goblet cell area in all 3 intestinal sections evaluated. Administering GLP2 had a marked beneficial effect on intestinal growth, morphology, and reduced circulating APP in comparison with cows on a similar plane of nutrition. In conclusion, FR had detrimental effects on intestinal barrier integrity and administering GLP2 alleviated these negative effects.

\section{ACKNOWLEDGMENTS}

This project was supported, in part, by Elanco Animal Health (Greenfield, IN).

\section{REFERENCES}

Abuajamieh, M., S. K. Kvidera, M. V. Fernandez, A. Nayeri, N. C. Upah, E. A. Nolan, S. M. Lei, J. M. DeFrain, H. B. Green, K. M. Schoenberg, W. E. Trout, and L. H. Baumgard. 2016. Inflammatory biomarkers are associated with ketosis in periparturient Holstein cows. Res. Vet. Sci. 109:81-85.

AOAC International. 1995. AOAC official method 972.16: Fat, lactose, protein, and solids in milk. Mid-infrared spectroscopic method. Pages 23-26 in Official Methods of Analysis. 16th ed. Vol. 2. AOAC International, Arlington, VA.

Baumgard, L. H., G. J. Hausman, and M. V. Sanz Fernandez. 2016. Insulin: Pancreatic secretion and adipocyte regulation. Domest. Anim. Endocrinol. 54:76-84.

Baumgard, L. H., and R. P. Rhoads. 2013. Effects of heat stress on postabsorptive metabolism and energetics. Annu. Rev. Anim. Biosci. 1:311-337. https://doi.org/10.1146/annurev-animal $-031412-103644$.

Benjamin, M. A., D. M. McKay, P. C. Yang, H. Cameron, and M. H. Perdue. 2000. Glucagon-like peptide-2 enhances intestinal epithelial barrier function of both transcellular and paracellular pathways in the mouse. Gut 47:112-119.

Bjerre-Harpøth, V., N. C. Friggens, V. M. Thorup, T. Larsen, B. M. Damgaard, K. L. Ingvartsen, and K. M. Moyes. 2012. Metabolic and production profiles of dairy cows in response to decreased nutrient density to increase physiological imbalance at different stages of lactation. J. Dairy Sci. 95:2362-2380.

Boudry, G., V. Péron, I. Le Huërou-Luron, J. P. Lallès, and B. Sève. 2004. Weaning induces both transient and long-lasting modifications of absorptive, secretory, and barrier properties of piglet intestine. J. Nutr. 134:2256-2262.

Boushey, R. P., B. Yusta, and D. J. Drucker. 1999. Glucagon-like peptide 2 decreases mortality and reduces the severity of indomethacin-induced murine enteritis. Am. J. Physiol. 277:E937-E947.

Boza, J. J., D. Möennoz, J. Vuichoud, A. R. Jarret, D. Gaudardde-Weck, R. Fritsché, A. Donnet, E. J. Schiffrin, G. Perruisseau, and O. Ballévre. 1999. Food deprivation and refeeding influence growth, nutrient retention and functional recovery of rats. J. Nutr. 129:1340-1346.

Bueno-Silva, B., D. Kawamoto, E. S. Ando-Suguimoto, R. C. V. Casarin, S. M. Alencar, P. L. Rosalen, and M. P. A. Mayer. 2017. Brazilian red propolis effects on peritoneal macrophage activity: 
Nitric oxide, cell viability, pro-inflammatory cytokines and gene expression. J. Ethnopharmacol. 207:100-107.

Cameron, H. L., and M. H. Perdue. 2005. Stress impairs murine intestinal barrier function: improvement by glucagon-like peptide-2. J. Pharmacol. Exp. Ther. 314:214-220.

Cappellozza, B. I., R. F. Cooke, C. Trevisanuto, V. D. Tabacow, F. N. T. Cooke, and D. W. Bohnert. 2011. Feed and water restriction elicits an acute-phase protein response in beef cattle. J. Anim. Sci. 89(E-Suppl. S1):269. (Abstr.)

Carey, H. V., U. L. Hayden, and K. E. Tucker. 1994. Fasting alters basal and stimulated ion transport in piglet jejunum. Am. J. Physiol. 267:R156-R163.

Carlson, D. B., N. B. Litherland, H. M. Dann, J. C. Woodworth, and J. K. Drackley. 2006. Metabolic effects of abomasal L-carnitine infusion and feed restriction in lactating Holstein cows. J. Dairy Sci. 89:4819-4834.

Ceciliani, F., J. J. Ceron, P. D. Eckersall, and H. Sauerwein. 2012 Acute phase proteins in ruminants. J. Proteomics 75:4207-4231.

Chalmeh, A., K. Badiei, M. Pourjafar, and S. Nazifi. 2013. Anti-inflammatory effects of insulin regular and flunixin meglumin on endotoxemia experimentally induced by Escherichia coli serotype O55:B5 in an ovine model. Inflamm. Res. 62:61-67.

Chappell, V. L., M. D. Thompson, M. G. Jeschke, D. H. Chung, J. C. Thompson, and S. E. Wolf. 2003. Effects of incremental starvation on gut mucosa. Dig. Dis. Sci. 48:765-769.

Connor, E. E., R. L. Baldwin, A. V. Capuco, C. M. Evock-Clover, S. E. Ellis, and K. S. Sciabica. 2010. Characterization of glucagonlike peptide 2 pathway member expression in bovine gastrointestinal tract. J. Dairy Sci. 93:5167-5178.

Connor, E. E., C. M. Evock-Clover, E. H. Wall, R. L. Baldwin, M. Santin-Duran, T. H. Elsasser, and D. M. Bravo. 2016. Glucagonlike peptide 2 and its beneficial effects on gut function and health in production animals. Domest. Anim. Endocrinol. 56:S56-S65.

Connor, E. E., S. Kahl, T. H. Elsasser, R. L. Baldwin, R. Fayer, M. Santin-Duran, G. L. Sample, and C. M. Evock-Clover. 2013. Glucagon-like peptide 2 therapy reduces negative effects of diarrhea on calf gut. J. Dairy Sci. 96:1793-1802.

Connor, E. E., E. H. Wall, D. M. Bravo, C. M. Evock-Clover, T. H. Elsasser, R. L. Baldwin, M. Santín, B. T. Vinyard, S. Kahl, and M. P. Walker. 2017. Reducing gut effects from Cryptosporidium parvum infection in dairy calves through prophylactic glucagonlike peptide 2 therapy or feeding of an artificial sweetener. J. Dairy Sci. 100:3004-3018.

de Boer, G., A. Trenkle, and J. W. Young. 1985. Glucagon, insulin, growth hormone, and some blood metabolites during energy restriction ketonemia of lactating cows. J. Dairy Sci. 68:326-337.

de Punder, K., and L. Pruimboom. 2015. Stress induces endotoxemia and low-grade inflammation by increasing barrier permeability. Front. Immunol. 6:223.

Deitch, E. A., W. J. Ma, L. Ma, R. D. Berg, and R. D. Specian. 1990 Protein malnutrition predisposes to inflammatory-induced gutorigin septic states. Ann. Surg. 211:560-567.

Doherty, J. F., M. H. Golden, J. G. Raynes, G. E. Griffin, and K. P. McAdam. 1993. Acute-phase protein response is impaired in severely malnourished children. Clin. Sci. (Lond.) 84:169-175.

Drucker, D. J., and B. Yusta. 2014. Physiology and pharmacology of the enteroendocrine hormone glucagon-like peptide-2. Annu. Rev. Physiol. 76:561-583.

Emmanuel, D. G., K. L. Madsen, T. A. Churchill, S. M. Dunn, and B. N. Ametaj. 2007. Acidosis and lipopolysaccharide from Escherichia coli B:055 cause hyperpermeability of rumen and colon tissues. J. Dairy Sci. 90:5552-5557.

Ferraretto, L. F., H. Gencoglu, K. S. Hackbart, A. B. Nascimento, F. Dalla Costa, R. W. Bender, J. N. Guenther, R. D. Shaver, and M. C. Wiltbank. 2014. Effect of feed restriction on reproductive and metabolic hormones in dairy cows. J. Dairy Sci. 97:754-763.

Ferraris, R. P., and H. V. Carey. 2000. Intestinal transport during fasting and malnutrition. Annu. Rev. Nutr. 20:195-219.

Ford, R. P., I. S. Menzies, A. D. Phillips, J. A. Walker-Smith, and M. W. Turner. 1985. Intestinal sugar permeability: relationship to diarrhoeal disease and small bowel morphology. J. Pediatr. Gastroenterol. Nutr. 4:568-574.

Fortun, P. J., and C. J. Hawkey. 2007. Nonsteroidal antiinflammatory drugs and the small intestine. Curr. Opin. Gastroenterol. $23: 134-141$

Guan, X. 2014. The CNS glucagon-like peptide-2 receptor in the control of energy balance and glucose homeostasis. Am. J. Physiol. Regul. Integr. Comp. Physiol. 307:R585-R596.

Guerville, M., and G. Boudry. 2016. Gastrointestinal and hepatic mechanisms limiting entry and dissemination of lipopolysaccharide into the systemic circulation. Am. J. Physiol. Gastrointest. Liver Physiol. 311:G1-G15.

Hodin, C. M., K. Lenaerts, J. Grootjans, J. J. de Haan, M. Hadfoune, F. K. Verheyen, H. Kiyama, E. Heineman, and W. A. Buurman. 2011. Starvation compromises Paneth cells. Am. J. Pathol 179:2885-2893.

Holt, P. R., S. Wu, and K. Y. Yeh. 1986. Ileal hyperplastic response to starvation in the rat. Am. J. Physiol. 251:G124-G131.

Hu, X. F., Y. M. Guo, B. Y. Huang, S. Bun, L. B. Zhang, J. H. Li, D. Liu, F. Y. Long, X. Yang, and P. Jiao. 2010. The effect of glucagon-like peptide 2 injection on performance, small intestinal morphology, and nutrient transporter expression of stressed broiler chickens. Poult. Sci. 89:1967-1974

Iseri, V. J., and K. C. Klasing. 2013. Dynamics of the systemic components of the chicken (Gallus domesticus) immune system following activation by Escherichia coli; implications for the costs of immunity. Dev. Comp. Immunol. 40:248-257.

Johnson, R. W. 2012. Fueling the immune response: What's the cost? Pages 211-223 in Feed Efficiency in Swine. John Patience, ed. Wageningen Academic Publishers, Wageningen, the Netherlands.

Kang, P., D. Toms, Y. Yin, Q. Cheung, J. Gong, K. De Lange, and J. Li. 2010. Epidermal growth factor-expressing Lactococcus lactis enhances intestinal development of early-weaned pigs. J. Nutr. 140:806-811.

Khafipour, E., D. O. Krause, and J. C. Plaizier. 2009. A grain-based subacute ruminal acidosis challenge causes translocation of lipopolysaccharide and triggers inflammation. J. Dairy Sci. 92:10601070 .

Kisielinski, K., S. Willis, A. Prescher, B. Klosterhalfen, and V. Schumpelick. 2002. A simple new method to calculate small intestine absorptive surface in the rat. Clin. Exp. Med. 2:131-135.

Kvidera, S. K., M. J. Dickson, M. Abuajamieh, D. B. Snider, M. V. Sanz Fernandez, J. S. Johnson, A. F. Keating, P. J. Gorden, H. B. Green, K. M. Schoenberg, and L. H. Baumgard. 2017a. Intentionally induced intestinal barrier dysfunction causes inflammation, affects metabolism, and reduces productivity in lactating Holstein cows. J. Dairy Sci. 100:4113-4127.

Kvidera, S. K., E. A. Horst, M. Abuajamieh, E. J. Mayorga, M. V. Fernandez, and L. H. Baumgard. 2017b. Glucose requirements of an activated immune system in lactating Holstein cows. J. Dairy Sci. 100:2360-2374

Kvidera, S. K., E. A. Horst, M. Abuajamieh, E. J. Mayorga, M. V Sanz Fernandez, and L. H. Baumgard. 2016. Technical note: A procedure to estimate glucose requirements of an activated immune system in steers. J. Anim. Sci. 94:4591-4599.

Le Floc'h, N., C. Knudsen, T. Gidenne, L. Montagne, E. Merlot, and O. Zemb. 2014. Impact of feed restriction on health, digestion and faecal microbiota of growing pigs housed in good or poor hygiene conditions. Animal 8:1632-1642.

Lee, S. J., J. Lee, K. K. Li, D. Holland, H. Maughan, D. S. Guttman, B. Yusta, and D. J. Drucker. 2012. Disruption of the murine Glp2r impairs Paneth cell function and increases susceptibility to small bowel enteritis. Endocrinology 153:1141-1151.

Lérias, J. R., R. Peña, L. E. Hernández-Castellano, J. Capote, N. Castro, A. Argüello, S. S. Araújo, Y. Saco, A. Bassols, and A. M. Almeida. 2015. Establishment of the biochemical and endocrine blood profiles in the Majorera and Palmera dairy goat breeds: the effect of feed restriction. J. Dairy Res. 82:416-425.

Lohuis, J. A., J. H. Verheijden, C. Burvenich, and A. S. van Miert. 1988. Pathophysiological effects of endotoxins in ruminants. 2 Metabolic aspects. Vet. Q. 10:117-125. 
Mani, V., T. E. Weber, L. H. Baumgard, and N. K. Gabler. 2012. Growth and Development Symposium: Endotoxin, inflammation, and intestinal function in livestock. J. Anim. Sci. 90:1452-1465.

Marques, R. S., R. F. Cooke, C. L. Francisco, and D. W. Bohnert. 2012. Effects of twenty-four hour transport or twenty-four hour feed and water deprivation on physiologic and performance responses of feeder cattle. J. Anim. Sci. 90:5040-5046.

Minuti, A., S. Ahmed, E. Trevisi, F. Piccioli-Cappelli, G. Bertoni, N. Jahan, and P. Bani. 2014. Experimental acute rumen acidosis in sheep: consequences on clinical, rumen, and gastrointestinal permeability conditions and blood chemistry. J. Anim. Sci. 92:3966-3977.

Moeser, A. J., C. V. Klok, K. A. Ryan, J. G. Wooten, D. Little, V. L. Cook, and A. T. Blikslager. 2007. Stress signaling pathways activated by weaning mediate intestinal dysfunction in the pig. Am. J. Physiol. Gastrointest. Liver Physiol. 292:G173-G181.

Morey, S. D., L. K. Mamedova, D. E. Anderson, C. K. Armendariz, E. C. Titgemeyer, and B. J. Bradford. 2011. Effects of encapsulated niacin on metabolism and production of periparturient dairy cows. J. Dairy Sci. 94:5090-5104.

Mowat, A. M., and W. W. Agace. 2014. Regional specialization within the intestinal immune system. Nat. Rev. Immunol. 14:667-685.

Murphy, K. 2012. The mucosal immune system. Pages 465-507 in Janeway's Immunobiology. 8th ed. Garland Science, New York, NY.

NRC. 2001. Nutrient Requirements of Dairy Cattle. 7th rev. ed. Natl. Acad. Press, Washington, DC.

Overman, E. L., J. E. Rivier, and A. J. Moeser. 2012. CRF induces intestinal epithelial barrier injury via the release of mast cell proteases and TNF- $\alpha$. PLoS One 7:e39935.

Pearce, S. C., V. Mani, T. E. Weber, R. P. Rhoads, J. F. Patience, L. H. Baumgard, and N. K. Gabler. 2013. Heat stress and reduced plane of nutrition decreases intestinal integrity and function in pigs. J. Anim. Sci. 91:5183-5193.

Reid, M., A. Badaloo, T. Forrester, J. F. Morlese, W. C. Heird, and F. Jahoor. 2002. The acute-phase protein response to infection in edematous and nonedematous protein-energy malnutrition. Am. J. Clin. Nutr. 76:1409-1415.

Rhoads, R. P., J. W. Kim, B. J. Leury, L. H. Baumgard, N. Segoale, S. J. Frank, D. E. Bauman, and Y. R. Boisclair. 2004. Insulin increases the abundance of the growth hormone receptor in liver and adipose tissue of periparturient dairy cows. J. Nutr. 134:1020-1027.

Rodriguez, P., N. Darmon, P. Chappuis, C. Candalh, M. A. Blaton, C. Bouchaud, and M. Heyman. 1996. Intestinal paracellular permeability during malnutrition in guinea pigs: Effect of high dietary zinc. Gut 39:416-422.

Schmidt, W. E., E. G. Siegel, and W. Creutzfeldt. 1985. Glucagon-like peptide-1 but not glucagon-like peptide-2 stimulates insulin release from isolated rat pancreatic islets. Diabetologia 28:704-707.

Shao, J., B. Zhang, J. J. Yu, C. Y. Wei, W. J. Zhou, K. K. Chang, H. L. Yang, L. P. Jin, X. Y. Zhu, and M. Q. Li. 2016. Macrophages promote the growth and invasion of endometrial stromal cells by downregulating IL-24 in endometriosis. Reproduction 152:673-682.

Steele, M. A., G. B. Penner, F. Chaucheyras-Durand, and L. Guan. 2016. Development and physiology of the rumen and the lower gut: Targets for improving gut health. J. Dairy Sci. 99:4955-4966.
Taylor-Edwards, C. C., D. G. Burrin, J. J. Holst, K. R. McLeod, and D. L. Harmon. 2011. Glucagon-like peptide-2 (GLP-2) increases small intestinal blood flow and mucosal growth in ruminating calves. J. Dairy Sci. 94:888-898.

Thyagarajan, N., J. D. Marshall, A. T. Pickett, C. Schumacher, Y. Yang, S. L. Christian, and R. J. Brown. 2017. Transcriptomic analysis of THP-1 macrophages exposed to lipoprotein hydrolysis products generated by lipoprotein lipase. Lipids 52:189-205.

Thymann, T., I. Le Huërou-Luron, Y. M. Petersen, M. S. Hedemann, J. Elinf, B. B. Jensen, J. J. Holst, B. Hartmann, and P. T. Sangild. 2014. Glucagon-like peptide 2 treatment may improve intestinal adaptation during weaning. J. Anim. Sci. 92:2070-2079.

Tůmová, E., Z. Volek, D. Chodová, H. Härtlová, P. Makovický, J. Svobodová, T. A. Ebeid, and L. Uhlírová. 2016. The effect of 1-week feed restriction on performance, digestibility of nutrients and digestive system development in the growing rabbit. Animal 10:1-9.

Ueno, P. M., R. B. Oriá, E. A. Maier, M. Guedes, O. G. de Azevedo, D. Wu, T. Willson, S. P. Hogan, A. A. Lima, R. L. Guerrant, D. B. Polk, L. A. Denson, and S. R. Moore. 2011. Alanyl-glutamine promotes intestinal epithelial cell homeostasis in vitro and in a murine model of weanling undernutrition. Am. J. Physiol. Gastrointest. Liver Physiol. 301:G612-G622.

van Miert, A. S., and J. Frens. 1968. The reaction of different animal species to bacterial pyrogens. Zentralbl. Veterinarmed. A 15:532543.

Vanuytsel, T., S. van Wanrooy, H. Vanheel, C. Vanormelingen, S. Verschueren, E. Houben, S. Salim Rasoel, J. Tóth, L. Holvoet, R. Farré, L. Van Oudenhove, G. Boeckxstaens, K. Verbeke, and J. Tack. 2014. Psychological stress and corticotropin-releasing hormone increase intestinal permeability in humans by a mast celldependent mechanism. Gut 63:1293-1299.

Walker, M. P., C. M. Evock-Clover, T. H. Elsasser, and E. E. Connor. 2015. Short communication: Glucagon-like peptide- 2 and coccidiosis alter tight junction gene expression in the gastrointestinal tract of dairy calves. J. Dairy Sci. 98:3432-3437.

Welsh, F. K., S. M. Farmery, K. MacLennan, M. B. Sheridan, G. R. Barclay, P. J. Guillou, and J. V. Reynolds. 1998. Gut barrier function in malnourished patients. Gut 42:396-401.

Wirtz, S., C. Neufert, B. Weigmann, and M. F. Neurath. 2007. Chemically induced mouse models of intestinal inflammation. Nat. Protoc. 2:541-546.

Xie, S., B. Liu, S. Fu, W. Wang, Y. Yin, N. Li, W. Chen, J. Liu, and D. Liu. 2014. GLP-2 suppresses LPS-induced inflammation in macrophages by inhibiting ERK phosphorylation and NF- $\kappa \mathrm{B}$ activation. Cell. Physiol. Biochem. 34:590-602.

Yamauchi, K., H. Kamisoyama, and Y. Isshiki. 1996. Effects of fasting and refeeding on structures of the intestinal villi and epithelial cells in White Leghorn hens. Br. Poult. Sci. 37:909-921.

Zhang, S., R. I. Albornoz, J. R. Aschenbach, D. R. Barreda, and G. B. Penner. 2013. Short-term feed restriction impairs the absorptive function of the reticulo-rumen and total tract barrier function in beef cattle. J. Anim. Sci. 91:1685-1695. 